\title{
Happy Wife, Happy Life: Food Choices in Romantic Relationships
}

\author{
JONATHAN HASFORD
}

BLAIR KIDWELL

VIRGINIE LOPEZ KIDWELL

Forthcoming, Journal of Consumer Research 
Jonathan Hasford (jonathan.hasford@ucf.edu, 407-823-3001) is Assistant Professor of Marketing, University of Central Florida, Orlando, FL 32826. Blair Kidwell (Blair.Kidwell@unt.edu, 940-565-2985) is Associate Professor of Marketing, University of North Texas, Denton, TX, 76203. Virginie Lopez-Kidwell (Virginie.Kidwell@unt.edu, 940-5653060) is Assistant Professor of Management, University of North Texas, Denton, TX, 76203. Correspondence: Jonathan Hasford. The authors thank the JCR review team for their excellent guidance throughout the review process. The authors also thank David Hardesty, Rob Richerson, Maura Scott, Brian Murtha, and Ze Wang for their helpful feedback on earlier drafts of the paper. Supplementary materials are included in the web appendix accompanying the online version of this article.

Darren Dahl served as editor and Jaideep Sengupta served as associate editor for this article. 


\begin{abstract}
The authors extend research on dyadic decision making by examining how relationship partners influence consumer eating patterns. Using research from relationship science and evolutionary psychology, romantic relationship motives of formation and maintenance are found to influence eating behaviors. Specifically, females are influenced by the eating patterns (i.e., healthiness/unhealthiness) of males when relationship formation motives are active, while males are influenced by the eating patterns of females when relationship maintenance motives are active. Furthermore, perceptions of relational influence differ between relationship formation and maintenance, which underlies these observed effects. This research contributes to the consumer behavior literature by revealing the powerful influence of relationships on food consumption.
\end{abstract}

Keywords: influence, relationships, food choice, joint decision making 
Individual decision making is often affected by interpersonal influence from friends, coworkers, and family. These sources of social influence are highly impactful in domains such as attitude formation, product consumption, and reference group affiliation (Cialdini and Trost 1998; Dahl 2013; Wood 2000). Within the context of interpersonal influence, perhaps no source of influence is more powerful than one's romantic partner. Due to the unique sharing of resources and goals in a romantic partnership, individuals are regularly affected by the preferences and beliefs of their partners. For example, individuals in a romantic relationship may incorporate their partner's attitudes and beliefs into choice processes (Kirchler 2001; Simpson, Griskevicius, and Rothman 2012; Su et al. 2008), self-sacrifice for the well-being of their partner (Durante et al. 2016; Van Lange et al. 1997), and adopt approach-oriented goals to better respond to their partner's needs (Impett et al. 2010). Together, these findings suggest that one's romantic partner is often a powerful source of influence in the decision making process.

Despite these important studies, research has been surprisingly limited on the influence of one's romantic partner in one of the most common and frequently made joint decisions - food choice. Research estimates that couples eat approximately half of their meals together (Sobal and Nelson 2003), and shared meals are a common activity for couples in both forming and maintaining their relationships. Furthermore, examining food choice within romantic relationships may provide crucial insights on why individuals consume unhealthy foods and when health-related issues such as obesity may emerge. For example, a common first date activity for couples is going out for dinner. Might a man's or woman's food choices be susceptible to influence from their partner through a desire to form a romantic partnership? Additionally, for couples who want to maintain their current relationship, might an individual match the eating patterns of their partner to preserve relationship harmony or avoid conflict with 
their partner? Furthermore, what factors might underlie whether men or women are influenced by the food choices of their romantic partners?

In this research, we address these questions by examining how relationship motives can influence the food choices of males and females. Using research from relationship science and evolutionary psychology, we develop a conceptual model of relationship motives, gender, and influence in food choice. Specifically, we propose that when a relationship formation motive is active, women are more likely to be influenced by the food choices of their partners and select an unhealthier (healthier) meal when their partner chooses an unhealthy (healthy) meal. Conversely, when a relationship maintenance motive is active, men are more likely to be influenced by the food choices of their partners and select an unhealthier (healthier) meal when their partner chooses an unhealthy (healthy) meal. These predictions are examined across four studies, including a field study of couples at a national restaurant chain. Furthermore, we provide process evidence underlying our effects by identifying how perceptions of relational influence shift from relationship formation to maintenance. Together, our research contributes to the literature on social influence in food choice (Ariely and Levav 2000; McFerran et al. 2010) by demonstrating how relationship motives can guide food decisions within a romantic relationship.

\section{Conceptual Background}

Romantic partners frequently engage in joint decision making. Models of decision making have identified several factors that influence dyadic choice processes, including the valence of shared attitudes, the strength and conviction of each individual's beliefs, and how joint preferences develop over time (Simpson et al. 2012). Individual differences can also impact 
models of dyadic decision making. For instance, anxious individuals may feel insecure about their relationship and thus are more likely to agree with their partners to reinforce commitment (Campbell et al. 2001; Tran and Simpson 2009). Related research indicates that differences in goals can impact partner responsiveness to each other's preferences and ultimately influence long-term satisfaction with the relationship (Impett et al. 2010).

As couples integrate their personal preferences into joint decisions, each individual will use various influence strategies to affect the other's preferences and decision making (Su et al. 2008). For example, couples may attempt to bargain with each other, play on emotions, or utilize compromise strategies to resolve conflict in product choice decisions (Kim and Lee 1996; Park 1982). Similarly, individuals may use direct or indirect communication strategies to influence and change their partner's behavior (Overall et al. 2009). The use of these various tactics is based on multiple factors, including perceptions of authority within the relationship, contributions of resources to the relationship, and prior attempts at influence and control (Lee and Beatty 2002; Simpson et al. 2012).

Interdependence theory (Kelley and Thibaut 1978) provides insights on when individuals may be susceptible to influence from their romantic partners. Interdependence theory proposes that a person's dependence on their partner is based on the degree to which their partner provides them with unique or desired benefits in their relationship. For example, if a woman is provided love, compassion, or support by her husband that other relationships do not provide, she becomes dependent on her husband for those benefits. As this dependence increases, she becomes more susceptible to influence from her partner.

We use prior literature on romantic relationships, influence strategies, and decision making to form our primary predictions. Specifically, we propose that influence between 
partners will vary at different stages of a romantic relationship, ultimately impacting whether men or women are susceptible to influence from their partner's food choices. In the sections that follow, we examine two fundamental romantic relationship motives (formation and maintenance) and examine how differences in relational influence vary by gender across these motives to impact food choice decisions.

\section{Relationship Formation}

To fulfill a multitude of social and evolutionary needs, humans are innately motivated to form romantic relationships with others (Bowlby 1969; Kenrick et al. 2010). When forming a romantic relationship, individuals may use a variety of signaling tactics to persuade and convince others why they would be a suitable partner. We propose that fundamental differences in how males and females approach the formation of romantic relationships impacts perceptions of relational influence and induces women to be susceptible to influence from men.

A challenge facing men in the formation of relationships involves signaling why they are a desirable romantic partner given women's greater selectivity in forming romantic partnerships (Buss 1988; Kenrick et al. 2010). As a result, social norms dictate that men typically initiate romantic advances and choose dating activities (e.g. selecting a restaurant for dinner) in the early stages of a relationship (Rose and Frieze 1993). Furthermore, to influence potential partners, men often engage in various overt behaviors such as status displays and conspicuous consumption to facilitate the formation of romantic relationships (Greenlees and McGrew 1994; Sundie et al. 2011). Because women are attracted to men with resources and high earning potential for long- 
term partnerships (Eastwick and Finkel 2008), men engage in these behaviors to signal their value and influence potential partners during relationship formation.

Women also use signaling behaviors during relationship formation. However, the signals women use suggests they may initially cede influence to their partner and be impacted by their choices. For example, while women often eat salads and other healthy foods on a first date as an appearance-enhancing signal (Amiraian and Sobal 2009; Vartanian, Herman, and Polivy 2007), women also often act in an agreeable manner to highlight potential commonalities that facilitate the development of relationships (Ashton-James et al. 2007; Cross and Madison 1997). Whereas women are not attracted to an agreeable man during relationship formation, men's desire for agreeable partner can lead women to initially accommodate a man's preferences (Luo and Zhang 2009). Furthermore, both men and women possess lay beliefs that a woman is more likely to secure a long-term partner if they display an agreeable nature and initially conform to the preferences of a man (Campbell 2002; Hornsey et al. 2015). Thus, due to the relational benefits of agreeing with the preferences of others, we expect that women will be influenced by the eating patterns of a man during relationship formation.

Together, these findings lead to our primary predictions for relationship formation. When forming a relationship, the relational norms associated with men initiating romantic advances, as well as lay beliefs associated with how women can effectively form romantic relationships, should lead both men and women to perceive that men have enhanced relational influence. For food choice decisions in particular, we predict that the enhanced relational influence of men will increase women's susceptibility to influence from their partners and thus lead women to consume unhealthier foods when their partner selects an unhealthy (relative to a healthy) meal. 
Conversely, since men are perceived to have enhanced relational influence during relationship formation, we do not expect them to be significantly impacted by their partner's food choices.

Relationship Maintenance

Once a romantic relationship is established, individuals are often motivated to maintain their relationship. Individuals with a relationship maintenance motive may engage in directed acts toward their partner (e.g. buying a gift, demonstrating love and care), respond to others outside of the relationship (e.g. women engaging in conspicuous consumption to deter rivals; Wang and Griskevicius 2014), or self-sacrifice for the benefit of their relationship (Durante et al. 2016) to reinforce commitment. Furthermore, individuals with a maintenance motive more frequently engage in joint decision making and rely on their partner's perceived competencies to facilitate choice processes (Simpson et al. 2012; Su et al. 2008). Based on differences in men's and women's maintenance behaviors, we propose that women will gain relational influence in food decisions and men will subsequently be impacted by the food choices of their female partners.

We suggest two reasons as to why men are susceptible to women's influence in food choice during relationship maintenance. First, men often exhibit a more agreeable nature during relationship maintenance. Research has identified a demand-withdraw pattern in relationships, whereby women often attempt to influence their spouses in decision making while men typically withdraw in an effort to prevent potential conflict (Christensen 1987; Kirkpatrick and Davis 1994; Stets and Hammons 2002). For example, males frequently accept their partner's choices given the importance they place on maintaining relationship harmony (Buss and Shackelford 
1997; de Miguel and Buss 2011; Kardum, Hudek-Knežević, and Gračanin 2006). Furthermore, men often act in accordance with their partner's preferences given that agreeableness in men is linked to greater relationship and sexual satisfaction (Botwin, Buss, and Shackelford 1997; Donnellan, Conger, and Bryant 2004; Malouff et al. 2010).

Secondly, when making joint decisions, a common strategy involves relying on the perceived competence and expertise of one's partner to make decisions for the couple (Carli 2001; Cavanaugh 2016; Park 1982). Thus, we propose that men's susceptibility to influence from women stems from women's enhanced relational influence in the food domain. Sociocultural perspectives suggest that women gain relational influence over their male partners as a relationship matures (Diekman, Goodfriend, and Goodwin 2004), particularly in domains where women are perceived to have competence and expertise (Carli 2001). One such domain is food choice, where research has noted that men often defer to women given women's knowledge of food preparation (Bove, Sobal, and Rauschenbach 2003; Devault 1994) and women's greater interest in health and nutrition (Allen, Griffith, and Gaines 2013). This perceived expertise leads women to predominately be responsible for household food decisions such as grocery purchases (Jackson, McDaniel, and Rao 1985; Nickols and Fox 1983; Roberts and Wortzel 1979). Based on these findings, we propose that individuals with a maintenance motive will perceive a shift in relational influence. We expect both men and women in relationship maintenance to perceive that women have enhanced relational influence in food choice decisions.

Together, these findings lead us to our core predictions for individuals with a relationship maintenance motive. We anticipate that perceptions of relational influence will change, such that both men and women will perceive that women have enhanced influence in the food domain. As a result, men are more likely to be impacted by the food decisions of their female partners. 
Specifically, men should consume healthier foods when their partner selects a healthy (versus unhealthy) meal. Conversely, given women's enhanced relational influence when a maintenance goal is active, women should not be significantly impacted by their partner's food choices.

Plan of Studies

Four studies were conducted to examine the impact of romantic partners on food choice. Study 1 captures the actual food choices of couples after dining at a nationwide restaurant chain. Study 2 experimentally manipulates relationship motives and examines their impact on food choice. Study 3 provides initial evidence that perceptions of relational influence underlie why individuals are influenced by their partner's choices. Lastly, study 4 directly measures perceptions of relational influence to provide additional evidence of our conceptual model.

\section{Study 1: Field Study of Relationships and Influence in Food Choice}

Study 1 was designed to initially test our conceptual model of relationship motives, influence, and food choice. To enhance external validity, couples who had just eaten dinner at a national restaurant chain were recruited as they were leaving the restaurant.

Method

One-hundred twenty-six male-female couples were recruited to participate in this study. When male-female pairs exited the restaurant, they were asked if they were a couple or dating 
and, if so, to participate in a brief research study. After providing consent, they were handed a restaurant menu and one survey per couple. To begin, couples indicated whether the male or female selected their meal first. This was used to examine whether their partner's food choices were influenced by what they selected. For example, if the female selected first, the male's food choices served as the DV in our analyses. Then each partner selected all the items they had in their meal using the restaurant menu to enhance recall. They listed all items as stated in the menu along with any requested changes and quantities for each item. To conclude, participants reported their relationship status (dating, engaged, or married).

Total calories for each individual were computed using nutritional information provided by the restaurant's website. Furthermore, two independent coders, unaware of the research hypotheses, also rated the healthiness of each individual's meal on a 5-point scale (1 - very unhealthy to 5 - very healthy). The coders were given information from multiple online nutrition resources (e.g. eatingrules.com, www.everydayhealth.com, www.hungry-girl.com) to assist in their codings. The coders were reliable in rating the healthiness of the men's $(\mathrm{r}=.78, p<.001)$ and women's $(\mathrm{r}=.88, p<.001)$ choices. The average healthiness rating was computed for each individual's meal, and this measure was negatively correlated with total calories consumed by each individual $(\mathrm{r}=-.43, p<.001)$. Lastly, couples that were dating were coded as having a relationship formation motive, while couples that were engaged or married were coded as having a relationship maintenance motive given their pre-existing long-term commitment to each other.

\section{Results}

To analyze the interaction of partner influence, relationship motive, and partner's 
healthiness on the meal healthiness of who decided second, we used Model 3 (see appendix) in the PROCESS macro (Hayes 2013) as this model is specifically designed to examine three-way interactions in regression analysis. Full results for each study are available in the Web Appendix. A significant interaction of partner influence, relationship motive, and partner's healthiness was observed $(\mathrm{B}=1.73, \mathrm{t}=5.88, p<.001)$. The influence of the partner's choices on meal healthiness is displayed in figure 1. For couples with a relationship formation motive, the healthiness of females' choices was significantly positively related to the healthiness of their partner's meal when the male selected first $(\mathrm{t}=5.04, p<.001)$. However, the healthiness of the males' choices was significantly negatively related to the healthiness of their partner's meal when the female selected first $(\mathrm{t}=-3.03, p=.003)$. This finding suggests that males made selections in an opposite manner of their partners when couples possessed a relationship formation motive. Conversely, for couples with a relationship maintenance motive, the healthiness of males' choices was significantly positively related to the healthiness of their partner's meal when the female selected first $(\mathrm{t}=4.42, p<.001)$. However, the healthiness of the females' choices was not impacted by the healthiness of their partner's meal when the male selected first $(\mathrm{t}=1.18, p=.24)$. These results support our proposed model.

Insert figure 1 about here

We also analyzed the total calories consumed by each individual to provide further evidence of our proposed model. To analyze the interaction of partner influence (whether the male or female decided first), relationship motive, and partner's calories on total calories consumed (of who decided second), we again used Model 3 in the PROCESS macro (Hayes 
2013). A significant interaction of partner influence, relationship motive, and partner's calories was observed $(\mathrm{B}=-1.53, \mathrm{t}=-4.56, p<.001)$. For couples with a relationship formation motive, male calories consumed significantly predicted the amount of calories consumed by the female when the male decided first $(\mathrm{t}=4.87, p<.001)$. However, calories consumed by the female was not predictive of male calories consumed when the female decided first $(\mathrm{t}=.37, p=.71)$. Conversely, for couples with a relationship maintenance motive, female calories consumed significantly predicted the number of calories consumed by the male when the female decided first $(\mathrm{t}=4.96, p<.001)$. However, calories consumed by the male was not predictive of female calories consumed when the male decided first $(\mathrm{t}=1.37, p=.17)$. Together, these results further support our conceptual model.

\section{Discussion}

Using a sample of participants who had just eaten dinner at a national restaurant chain, study 1 provides initial evidence for our conceptual model of relationship motives and food choice. When couples were dating (i.e. relationship formation) and the male selected his meal first, females were influenced by the healthiness and calories of their partner's meal. Conversely, when couples were engaged/married (i.e. relationship maintenance) and the female selected her meal first, males were influenced by the healthiness and calories of their partner's meal. To further investigate these findings, in study 2 we experimentally manipulate relationship motives and examine their impact on food choice.

\section{Study 2: Manipulating Relationship Motives}


Study 2 was designed to extend the findings of our field study by experimentally manipulating relationship motives. We used romantic relationship scenarios to activate formation and maintenance motives. After reading the scenarios, participants then completed a food choice task involving a hypothetical opposite sex partner.

\section{Method}

Two-hundred ninety-two undergraduate students ( $54.8 \%$ female) were randomly assigned to a 2 (relationship motive: formation/maintenance) $\times 2$ (partner's eating style: healthy/unhealthy) between-subjects design. To begin, participants indicated their gender. All experimental manipulations then referred to a person of the opposite sex. Adapting procedures from Durante and Arsena (2015), participants read a vignette designed to activate either a relationship formation or relationship maintenance motive and then completed a writing task.

Both vignettes involved attending a party. In the relationship formation condition, participants were told to imagine they were single and meeting lots of attractive and friendly people of the opposite sex. In the relationship maintenance condition, participants were told to imagine they were at a party with their significant other and their partner was demonstrating a variety of loving and caring behaviors. The vignettes are available in the Appendix. After reading the vignette, participants were asked to write about the person they imagined, the setting they envisioned, and the emotions they felt to strengthen the priming effect.

After the writing task, participants were asked to imagine themselves at a restaurant eating with the person described in the scenario. The style of the dining partner was manipulated 
at this point. In the unhealthy partner condition, the partner chose lasagna with French onion soup, cheesecake for dessert, and a soda to drink. In the healthy partner condition, the partner chose grilled salmon with rice and vegetables, mixed fruit for dessert, and a water to drink. Participants then viewed a menu with a variety of appetizers, entrees, desserts, and drinks, which included the items that their partner selected. Each food item was individually coded as either healthy or unhealthy based on the results of a pretest (see Web Appendix for details). Participants were instructed to select one item from each section of the menu to make up a threecourse meal plus a drink. The percentage of healthy selections made was computed for each participant across the four total food choices, which served as our primary dependent variable.

After the menu task, participants completed several measures to assess whether individual differences in susceptibility to influence impacted our results. Self-monitoring was assessed via a 13-item scale measuring individual differences related to social interactions ( $\alpha=$ .76; Lennox and Wolfe 1984). One's desire to ingratiate themselves to others was measured with an 8-item scale from Bolino and Turnley $(1999 ; \alpha=.71)$. The Attention to Social Comparison Information scale (Bearden and Rose 1990) was collected to control for consumer conformity to others $(\alpha=.82)$. Furthermore, involvement with the decision task was measured via a 4-item scale $(\alpha=.76$; Zaichkowsky 1985$)$ adapted to food choice.

Participants then completed a series of manipulation checks. Participants completed three items measuring activation of relationship formation motives ("During the food choice task, I thought about forming a relationship", "During the food choice task, I thought about attracting a romantic partner", and "During the food choice task, I thought about meeting new people"; strongly disagree-strongly agree; $\alpha=.79$ ) and three items measuring activation of relationship maintenance motives ("During the food choice task, I thought about commitment", "During the 
food choice task, I thought about being in a relationship", and "During the food choice task, I thought about maintaining a romantic relationship"; strongly disagree-strongly agree; $\alpha=.80$ ) on 5-point scales. Participants then indicated whether their eating partner selected a healthy or unhealthy meal to serve as a manipulation check of perceptions of their partner's meal. Lastly, participants indicated their sexual orientation (straight, gay, bisexual, or prefer not to answer).

Results

Fifteen participants $(5.1 \%)$ indicated their sexual orientation as gay/preferred not to answer. Because our study involved romantic partners of the opposite sex to appeal specifically to straight or bisexual participants, we excluded those individuals who did not indicate that they were straight or bisexual. Therefore, 277 participants were retained for subsequent analyses.

Manipulation Checks. To begin, we examined whether our manipulation of relationship motives had their intended effect. We conducted an ANOVA with relationship motives and partner's eating style predicting activation of relationship formation. Results revealed a significant main effect of relationship motives on activation of relationship formation $(\mathrm{F}(1,273)$ $=45.68, p<.001)$. Furthermore, the effect of partner's eating style $(\mathrm{F}(1,273)=.07, p>.05)$ and the interaction of relationship motives and partner's eating style $(\mathrm{F}(1,273)=.25, p>.05)$ were non-significant. Participants in the relationship formation condition $(\mathrm{M}=3.42)$ reported significantly higher thoughts of relationship formation during the food choice task relative to participants in the relationship maintenance condition $(\mathrm{M}=2.55, p<.001)$.

We also conducted an ANOVA with relationship motives and partner's eating style predicting activation of relationship maintenance. Results revealed a significant main effect of 
relationship motives on activation of relationship maintenance $(\mathrm{F}(1,273)=4.86, p<.05)$.

Furthermore, the effect of partner's eating style $(\mathrm{F}(1,273)=.60, p>.05)$ and the interaction of relationship motive and partner's eating style $(\mathrm{F}(1,273)=.17, p>.05)$ were non-significant. Participants in the relationship maintenance condition $(\mathrm{M}=3.39)$ reported significantly higher thoughts of relationship maintenance during the food choice task relative to participants in the relationship formation condition $(\mathrm{M}=3.09, p<.05)$.

Next, we examined whether participants correctly perceived the healthiness of their partner's meal. A logistic regression was conducted with relationship motives and partner's eating style predicting perceptions of the partner's meal. A main effect of partner's eating style was observed $(\beta=4.96$, Wald $=22.88, p<.001)$. The main effect of relationship motives $(\beta=$ .85 , Wald $=.47, p>.05)$ and the partner eating style $\mathrm{x}$ relationship motives interaction $(\beta=-.69$, Wald $=.29, p>.05)$ were non-significant. $97.7 \%$ of participants in the healthy dining partner conditions correctly identified that their partner selected a healthy meal, while $68.8 \%$ of participants in the unhealthy dining partner conditions correctly identified that their partner selected an unhealthy meal $\left(\chi^{2}=131.4, p<.001\right)$.

Relationship Motives and Food Choice. To examine differences in relationship motives and food choice, we conducted an ANOVA with gender, relationship motive, and partner's eating style predicting percentage of healthy foods selected. Results revealed a significant threeway interaction of gender, relationship motive, and partner's eating style $(\mathrm{F}(1,269)=13.78, p<$ $.001)$. The percentage of healthy foods selected by condition is available in figure 2 .

Insert figure 2 about here 
Planned contrasts revealed that for females in the relationship formation condition, the percentage of healthy foods selected was significantly lower when the partner selected an unhealthy meal $(\mathrm{M}=46.8 \%, \mathrm{SD}=27.6 \%)$ relative to when the partner selected a healthy meal $(\mathrm{M}=68.9 \%, \mathrm{SD}=27.3 \%, 95 \% \mathrm{CI}[-35.10,-9.19], p=.001)$. However, for males in the relationship formation condition, no differences were present in the percentage of healthy foods selected $\left(\mathrm{M}_{\text {healthy }}=57.8 \%\right.$ vs. $\left.\mathrm{M}_{\text {unhealthy }}=55.5 \%, 95 \% \mathrm{CI}[-14.06,9.48], p=.70\right)$.

For males in the relationship maintenance condition, planned contrasts revealed that the percentage of healthy foods selected was significantly lower when the partner selected an unhealthy meal $(\mathrm{M}=43.5 \%, \mathrm{SD}=28.2 \%)$ relative to when the partner selected a healthy meal $(\mathrm{M}=69.6 \%, \mathrm{SD}=22.2 \%, 95 \% \mathrm{CI}[-38.67,-13.48], p<.001)$. However, for females in the relationship formation condition, no differences were present in the percentage of healthy foods selected $\left(\mathrm{M}_{\text {healthy }}=53.7 \%\right.$ vs. $\mathrm{M}_{\text {unhealthy }}=54.9 \%, 95 \%$ CI $\left.[-11.37,13.80], p=.85\right)$.

Furthermore, we analyzed whether any of the individual difference variables (selfmonitoring, one's desire to ingratiate themselves to others, attention to social comparison information, and involvement) impacted our findings. None of these measures were predictive of food choice in our study design (all $p s>.15$ ) and our pattern of results was not impacted by any of these variables. Further discussion of these covariates is thus omitted.

\section{Discussion}

Study 2 provides additional support for our model of romantic partners' influence on food choice. When experimentally manipulating relationship motives, we found that females with a relationship formation motive were influenced by the food choices of their partner. 
Conversely, we found that males with a relationship maintenance motive were influenced by the food choices of their partner. Next, to provide initial process evidence for our conceptual model, we examine whether differences in relational influence underlie why individuals are impacted by the choices of their dining partners.

\section{Study 3: Examining Differences in Relational Influence}

Study 3 was designed to examine whether differences in relational influence underlie the effects observed in studies 1 and 2. If differences in relational influence can explain why an individual's food decisions are affected by the choices of their romantic partners, then other relationships where differences in relational influence exist should produce similar effects. For example, when an individual perceives that someone else has power, authority, or the ability to influence them, they are more likely to situationally monitor their behavior and act in accordance with that person (Keltner, Gruenfeld, and Anderson 2003). Thus, if perceptions of relational influence are causing individuals to be influenced the food choices of their romantic partner, individuals should also be influenced by others who also possess high levels of relational influence over them. Therefore, study 3 not only examined romantic partners, but also considered dining with other individuals who possess high levels of relational influence.

To identify individuals who possess high levels of relational influence, a pretest was conducted prior to study 3. Fifty-three participants answered three items related to perceptions of relational influence for relationships with one's boss, one's romantic partner, and a friend ("When thinking about my relationship with [my boss/my romantic partner/a friend], he/she", "has authority over me", "has influence over my activities", and "generally has more power than 
I do") on 5-point scales. A repeated-measures ANOVA revealed a significant within-subjects effect of perceptions of relational influence $(\mathrm{F}(2,52)=88.49, p<.01)$. Specifically, one's boss was viewed as having higher levels of relational influence $(M=3.92)$ relative to one's romantic partner $(\mathrm{M}=2.96, p<.01)$ and one's friend $(\mathrm{M}=2.37, p<.01)$. Thus, study 3 examines both dining with a romantic partner and with one's boss to provide initial evidence that perceptions of relational influence underlie our observed effects.

Method

Six-hundred eighty-five individuals were recruited from Amazon MTurk (56.9\% female) and randomly assigned to a 2 (relationship motive: formation/maintenance) x 2 (partner's eating style: healthy/unhealthy) $\times 2$ (dining partner: romantic/boss) between-subjects design. The procedures were identical to study 2 except for three notable differences. First, we included two additional vignettes to activate thoughts of relationship formation and maintenance when interacting with one's boss. Both vignettes also involved attending a party to match the romantic partner conditions. In the relationship formation with boss condition, participants were told to imagine they just started a new job and were attending a company party. Their boss then initiates a conversation and they get to know each other by discussing their hobbies and interests. In the relationship maintenance with boss condition, participants were told to imagine they were attending a company party and have known their boss for a long time. They then reminisce with their boss about their relationship at the party and learn new things about each other to build a closer relationship. The full vignettes are available in the appendix. 
Secondly, we manipulated the dining partner's choices with different selections from study 2 . In the healthy partner condition, participants were told that the person described in the previous scenario ordered grilled chicken with a plain sweet potato, a side salad, and a water to drink. In the unhealthy partner condition, participants were told that the person described in the previous scenario ordered a fried chicken sandwich with French fries, a soda, and a brownie.

Lastly, since we examined relationships with both romantic partners and one's boss, we adjusted our manipulation checks of relationship motives to more generally reflect thoughts of relationship formation and maintenance during the food choice task. After completing the food choice task, participants completed three items measuring relationship formation ("During the food choice task, I thought about forming a relationship", "During the food choice task, I thought about meeting new people", and "During the food choice task, I thought about how I would act when meeting others"; strongly disagree-strongly agree; $\alpha=.87$ ) and three items measuring relationship maintenance ("During the food choice task, I thought about long-term relationships", "During the food choice task, I thought about maintaining a close relationship", and "During the food choice task, I thought about ongoing relationships"; strongly disagreestrongly agree; $\alpha=.88$ ) on 5-point scales.

Results

Twenty-two participants in the romantic partner conditions indicated their sexual orientation as gay/preferred not to answer. Because our study involved romantic partners of the opposite sex to appeal specifically to straight or bisexual participants, we excluded those 
individuals who did not indicate that they were straight or bisexual. Therefore, 663 participants were retained for subsequent analyses.

Manipulation Checks. To begin, we examined whether our manipulation of relationship motives had their intended effect. We conducted an ANOVA with relationship motives, dining partner, and partner's eating style predicting activation of relationship formation. Results revealed a significant main effect of relationship motives on activation of relationship formation $(\mathrm{F}(1,655)=68.39, p<.001)$. All other main effects and interactions were non-significant. Participants in the relationship formation condition $(M=2.97)$ reported significantly higher thoughts of relationship formation during the food choice task relative to participants in the relationship maintenance condition $(\mathrm{M}=2.29, p<.01)$.

We also conducted an ANOVA with relationship motives, dining partner, and partner's eating style predicting activation of relationship maintenance. Results revealed a significant main effect of relationship motives on activation of relationship maintenance $(\mathrm{F}(1,655)=7.85, p<$ .01). All other main effects and interactions were non-significant. Participants in the relationship maintenance condition $(\mathrm{M}=2.94)$ reported significantly higher thoughts of relationship maintenance during the food choice task relative to participants in the relationship formation condition $(\mathrm{M}=2.69, p<.01)$.

Next, we examined whether participants correctly perceived the healthiness of their partner's meal. A logistic regression was conducted with relationship motives, dining partner, and partner's eating style predicting perceptions of the partner's meal. A main effect of partner's eating style was observed $(\beta=4.65, \mathrm{Wald}=59.77, p<.001)$. All other main effects and interactions were non-significant. $92.6 \%$ of participants in the healthy dining partner conditions correctly identified that their partner selected a healthy meal, while $80.9 \%$ of participants in the 
unhealthy dining partner conditions correctly identified that their partner selected an unhealthy meal $\left(\chi^{2}=364.5, p<.001\right)$.

Relationship Motives and Food Choice. To examine differences in relationship motives and food choice, we conducted an ANOVA with gender, relationship motive, dining partner, and partner's eating style predicting percentage of healthy foods selected. Results revealed a fourway interaction of gender, relationship motive, dining partner, and partner's eating style (F(1, $647)=5.44, p<.05)$. An ANOVA table with full results is available in the Web Appendix, and the percentage of healthy foods selected by condition is available in figure 3 .

Insert figure 3 about here

Dining with Romantic Partner. First, we examined the food choices of participants in the romantic partner conditions (see figure 3, panel A). Planned contrasts revealed that for females in the relationship formation condition, the percentage of healthy foods selected was significantly lower when the partner selected an unhealthy meal $(\mathrm{M}=47.5 \%, \mathrm{SD}=28.8 \%)$ relative to when the partner selected a healthy meal $(\mathrm{M}=68.1 \%, \mathrm{SD}=31.5 \%, 95 \% \mathrm{CI}[-33.18,-7.97], p=.002)$. However, for males in the relationship formation condition, no differences were present in the percentage of healthy foods selected $\left(\mathrm{M}_{\text {healthy }}=53.1 \%\right.$ vs. $\mathrm{M}_{\text {unhealthy }}=54.2 \%, 95 \%$ CI $[-12.84$, 14.93], $p=.88)$.

For males in the relationship maintenance condition, planned contrasts revealed that the percentage of healthy foods selected was significantly lower when the partner selected an unhealthy meal $(\mathrm{M}=39.4 \%, \mathrm{SD}=30.4 \%)$ relative to when the partner selected a healthy meal $(\mathrm{M}=58.8 \%, \mathrm{SD}=28.4 \%, 95 \% \mathrm{CI}[-32.80,-6.02], p=.005)$. However, for females in the 
relationship formation condition, no differences were present in the percentage of healthy foods selected $\left(\mathrm{M}_{\text {healthy }}=51.8 \%\right.$ vs. $\mathrm{M}_{\text {unhealthy }}=54.4 \%, 95 \%$ CI $\left.[-8.78,14.04], p=.65\right)$.

Dining with Boss. Next, we examined whether individuals were influenced by their partner's selections when dining with their boss (see figure 3, panel B). Recall that if relational influence underlies our observed effects, any relationship where individuals perceive that another possesses relational influence should lead them to be impacted by that individual's food choices. Since one's boss would possess relational influence over someone both during initial relationship formation as well as when that relationship is being maintained over time, we expect individuals to be impacted by their boss's choices regardless of their relationship motive or gender.

In the boss conditions, there was only a main effect of partner's eating style on the percentage of healthy foods selected $(\mathrm{F}(1,319)=41.29, p<.001$; all other main effects and interactions were not significant). Planned contrasts revealed that for males with a relationship formation motive, the percentage of healthy foods selected was significantly lower when one's boss selected an unhealthy meal $(\mathrm{M}=42.8 \%, \mathrm{SD}=27.2 \%)$ relative to when one's boss selected a healthy meal $(\mathrm{M}=60.3 \%, \mathrm{SD}=32.3 \%, 95 \% \mathrm{CI}[-31.07,-3.92], p=.012)$. For females with a relationship formation motive, the percentage of healthy foods selected was significantly lower when one's boss selected an unhealthy meal $(\mathrm{M}=41.9 \%, \mathrm{SD}=30.7 \%)$ relative to when one's boss selected a healthy meal $(\mathrm{M}=65.2 \%, \mathrm{SD}=32.4 \%, 95 \% \mathrm{CI}[-36.62,-10.03], p=.001)$. For males with a relationship maintenance motive, the percentage of healthy foods selected was significantly lower when one's boss selected an unhealthy meal $(\mathrm{M}=42.4 \%, \mathrm{SD}=30.9 \%)$ relative to when one's boss selected a healthy meal $(\mathrm{M}=62.5 \%, \mathrm{SD}=31.8 \%, 95 \% \mathrm{CI}[-35.61$, 4.54], $p=.012$ ). Lastly, for females with a relationship maintenance motive, the percentage of healthy foods selected was significantly lower when one's boss selected an unhealthy meal $(\mathrm{M}=$ 
$46.3 \%, \mathrm{SD}=31.4 \%)$ relative to when one's boss selected a healthy meal $(\mathrm{M}=72.2 \%, \mathrm{SD}=$ $24.3 \%, 95 \%$ CI $[-37.25,-14.41], p<.001)$.

Discussion

Study 3 provides initial evidence that perceptions of relational influence underlie our observed effects. When dining with one's boss (a relationship where individuals possess reduced relational influence), individual food choices were impacted in a similar manner as when women (men) with a relationship formation (maintenance) motive dined with a romantic partner. Together, these findings suggest that perceptions of relational influence play an important role in determining how individuals are impacted by the food choices of their romantic partners. Next, in study 4 we test our full conceptual model by directly measuring perceptions of relational influence when individuals possess different relationship motives.

\section{Study 4: Test of Conceptual Model}

Study 4 was designed to provide additional process evidence for our conceptual model of relationships, influence, and food choice. Specifically, we predict that relationship motives will impact perceptions of relational influence, such that men (women) are perceived to have enhanced influence in food choice during relationship formation (maintenance). Those perceptions of relational influence will subsequently affect the likelihood of being impacted by the choices of one's partner. When men are perceived to have enhanced relational influence, 
women should be impacted by their partner's choices. Conversely, when women are perceived to have enhanced relational influence, men should be impacted by their partner's choices.

Method

Three hundred fifty participants were recruited from Amazon MTurk (53.7\% female) and randomly assigned to a 2 (relationship motive: formation/maintenance) $\times 2$ (partner's eating style: healthy/unhealthy) between-subjects design. The procedures were similar to study 2 except for three notable differences. First, instead of using the writing task to prime relationship motives (study 2), we developed a slide show based on the procedures of Durante et al. (2015) to prime formation and maintenance motives. In the relationship formation condition, participants viewed four slides about meeting others of the opposite sex and the early stages of dating to prime relationship formation motives. In the relationship maintenance condition, participants viewed four slides about how couples maintain their relationships. The slides were displayed in a random order to participants for 15 seconds each and are available in the appendix.

Secondly, the healthy and unhealthy eating partner choices were modified from study 2 . We used the partner choices from study 3 here. During the food choice task, participants were also instructed to imagine dining with a romantic partner of the opposite sex.

Lastly, after completing the menu task, participants completed items designed to measure perceptions of relational influence. Participants completed five bipolar items measuring lay beliefs associated with men and women's influence in relationships when making food decisions ( $\alpha=.77)$. The items are available in the Appendix, and higher (lower) scores reflect beliefs that women (men) have greater relational influence when couples make food choice decisions. 
Results

Twelve participants (3.4\%) indicated their sexual orientation as gay/preferred not to answer. Because our study involved romantic partners of the opposite sex to appeal specifically to straight or bisexual participants, we excluded those individuals who did not indicate that they were straight or bisexual. Therefore, 338 participants were retained for subsequent analyses.

Manipulation Checks. To begin, we examined whether our manipulation of relationship motives had their intended effect. We conducted an ANOVA with relationship motives and partner's eating style predicting activation of relationship formation. Results revealed a significant main effect of relationship motives on activation of relationship formation $(\mathrm{F}(1,334)$ $=18.82, p<.001)$. Furthermore, the effect of partner's eating style $(\mathrm{F}(1,334)=.16, p>.05)$ and the interaction of relationship motives and partner's eating style $(\mathrm{F}(1,334)=.07, p>.05)$ were non-significant. Participants in the relationship formation condition $(M=3.16)$ reported significantly higher thoughts of relationship formation during the food choice task relative to participants in the relationship maintenance condition $(\mathrm{M}=2.66, p<.01)$.

We also conducted an ANOVA with relationship motives and partner's eating style predicting activation of relationship maintenance. Results revealed a significant main effect of relationship motives on activation of relationship maintenance $(\mathrm{F}(1,334)=9.80, p<.01)$. Furthermore, the effect of partner's eating style $(\mathrm{F}(1,334)=2.01, p>.05)$ and the interaction of relationship motive and partner's eating style $(\mathrm{F}(1,334)=1.11, p>.05)$ were non-significant. Participants in the relationship maintenance condition $(M=3.44)$ reported significantly higher 
thoughts of relationship maintenance during the food choice task relative to participants in the relationship formation condition $(\mathrm{M}=3.08, p<.01)$.

Next, we examined whether participants correctly perceived the healthiness of their partner's meal. A logistic regression was conducted with relationship motives and partner's eating style predicting perceptions of the partner's meal. A main effect of partner's eating style was observed $(\beta=4.04$, Wald $=58.21, p<.001)$. The main effect of relationship motives $(\beta=$ .00$, Wald $=1.00, p>.05)$ and the partner eating style $\mathrm{x}$ relationship motives interaction $(\beta=.14$, Wald $=.03, p>.05)$ were non-significant. Results revealed that $94.7 \%$ of participants in the healthy dining partner conditions correctly identified that their partner selected a healthy meal, while $77.2 \%$ of participants in the unhealthy dining partner conditions correctly identified that their partner selected an unhealthy meal $\left(\chi^{2}=181.2, p<.001\right)$.

Relationship Motives and Food Choice. To examine differences in relationship motives and food choice, we conducted an ANOVA with gender, relationship motive, and partner's eating style predicting percentage of healthy foods selected. Results revealed a significant interaction of gender, relationship motive, and partner's eating style $(\mathrm{F}(1,330)=7.68, p<.01)$. The percentage of healthy foods selected by condition is available in figure 4 .

Insert figure 4 about here

Planned contrasts revealed that for females in the relationship formation condition, the percentage of healthy foods selected was significantly lower when the partner selected an unhealthy meal $(\mathrm{M}=43.4 \%, \mathrm{SD}=28.2 \%)$ relative to when the partner selected a healthy meal $(\mathrm{M}=65.7 \%, \mathrm{SD}=26.7 \%, 95 \% \mathrm{CI}[-33.54,-11.07], p<.001)$. However, for males in the 
relationship formation condition, no differences were present in the percentage of healthy foods selected $\left(\mathrm{M}_{\text {healthy }}=47.7 \%\right.$ vs. $\mathrm{M}_{\text {unhealthy }}=49.3 \%, 95 \%$ CI $\left.[-13.48,16.59], p=.84\right)$.

For males in the relationship maintenance condition, planned contrasts revealed that the percentage of healthy foods selected was significantly lower when the partner selected an unhealthy meal $(\mathrm{M}=43.1 \%, \mathrm{SD}=32.5 \%)$ relative to when the partner selected a healthy meal $(\mathrm{M}=56.5 \%, \mathrm{SD}=31.9 \%, 95 \% \mathrm{CI}[-32.80, .18], p=.053)$. However, for females in the relationship formation condition, no differences were present in the percentage of healthy foods selected $\left(\mathrm{M}_{\text {healthy }}=53.9 \%\right.$ vs. $\left.\mathrm{M}_{\text {unhealthy }}=52.6 \%, 95 \% \mathrm{CI}[-8.78,14.04], p=.82\right)$.

Perceptions of Relational Influence. Next, we examined whether perceptions of relational influenced differ between relationship formation and relationship maintenance. We conducted an ANOVA with relationship motives and gender predicting perceptions of relational influence (see table 1 for means by condition). Results revealed a significant main effect of relationship motives on perceptions of relational influence $(\mathrm{F}(1,334)=11.35, p=.001)$, consistent with our theorizing. Specifically, participants in the relationship formation condition $(M=3.84)$ reported that men have more influence in food choice decisions relative to participants in the relationship maintenance condition $(\mathrm{M}=4.18, \mathrm{p}<.01)$, who reported that women have more influence in food choice decisions (based on our 7-point bipolar scale). Additionally, a main effect of gender unrelated to our theorizing was observed $(\mathrm{F}(1,334)=11.97, p=.001)$ and the interaction of relationship motives and gender $(\mathrm{F}(1,334)=.39, p>.05)$ was non-significant.

Insert table 1 about here 
Mediation Analysis. To test our full conceptual model, we conducted mediated moderation analyses using PROCESS Model 15 (Hayes 2013). In this model, the interaction of relationship motive and gender predicted whether individuals were influenced by their partner, relationship motive predicted perceptions of relational influence, and the interaction of perceptions of relational influence and gender predicted whether individuals were influenced by their partner (see Appendix). For our dependent variable, we coded whether a majority of foods selected were consistent with the healthiness or unhealthiness of their partner's meal to represent influence from one's dining partner. For example, an individual had to select 1 or fewer healthy foods when their partner selected an unhealthy meal or 3 or more healthy foods when their partner selected a healthy meal to be characterized as being influenced their partner. Using this dependent variable allows us to capture the influence of the partner's meal choices on the participant's food selections, whereas simply the percentage of healthy foods selected does not.

The index of mediated moderation in our model was significant (effect $=-.255,95 \%$ CI [$.571,-.060])$. Specifically, relationship motives significantly predicted perceptions of relational influence $(\beta=.35, \mathrm{t}=3.74, p<.001)$. Additionally, the interaction of perceptions of relational influence and gender impacted whether participants were influenced by their partner's choices ( $\beta$ $=-.74, \mathrm{t}=-2.62, p<.001)$. Conditional indirect effects of the interaction revealed a significant indirect effect of relationship motives on partner influence for both men (effect $=.117,95 \% \mathrm{CI}$ $[.006, .293])$ and women (effect $=-.139,95 \%$ CI $[-.369,-.005])$. The pattern of effects suggests that as women's perceived relational influence increases, men become more likely to be influenced by their partner's choices. Conversely, as men's perceived relational influence increases, women become more likely to be influenced by their partner's choices. 


\section{Discussion}

Study 4 provided additional process evidence for our conceptual model of relationships, influence, and food choice. Using a new manipulation of relationship motives, we replicated our previous findings. Additionally, mediated moderation analysis revealed that perceptions of relational influence shift across relationship motives, and those differences affect whether men or women are influenced by their partner's food choices. Together, these findings provide additional evidence that perceptions of relational influence underlie when men and women are impacted by their partner's food choice decisions.

\section{General Discussion}

The present research examines how food choices are impacted by romantic partners. We focus particularly on how males and females are influenced by the opposite sex depending on what relationship motives are active at the time of consumption. Four studies demonstrated that females are influenced by the eating patterns (i.e., healthiness/unhealthiness) of males when relationship formation motives are active, while males are influenced by the eating patterns of females when relationship maintenance motives are active. Furthermore, we provided evidence that perceptions of relational influence underlie our observed effects. When dining with one's boss (who possesses high levels of relational influence), the pattern of results was similar to females (males) in relationship formation (maintenance). Additionally, study 4 demonstrated that perceptions of relational influence mediate the relationship between motives, gender, and food choice. Together, these findings provide several theoretical and consumer implications. 
Theoretical Contributions

The current research makes several theoretical contributions to research on relationships, influence, and food choice. First, we extend previous studies of how one's romantic partner impacts decision making. While research has examined how individuals will incorporate their partner's preferences into attitude formation and choice processes (e.g., Kirchler 2001; Simpson et al. 2012; Su et al. 2008), studies have been limited on how one's partner, as well as the motives one holds toward that individual, impacts joint decisions within the food domain. For example, whereas previous research has shown that larger groups can enhance individual variety-seeking in food and beverage consumption (Ariely and Levav 2000), we specifically demonstrated how one's romantic partner can impact the healthiness or unhealthiness of foods that an individual chooses to consume.

We also identified how perceptions of relational influence underlie why females (males) with a relationship formation (maintenance) motive are impacted by the choices of their partners. We observed a shift in relational influence, whereby both males and females perceived that men (women) have greater relational influence in the food domain during relationship formation (maintenance). This finding extends research in several areas of romantic relationships, influence, and decision making, including studies of agreeableness in relationship formation (e.g., Eastwick and Finkel 2008; Luo and Zhang 2009) and demand-withdraw patterns of decision making in relationship maintenance (e.g., Ashton-James et al. 2007; Cross and Madison 1997). 
Our work also contributes to the food choice literature by examining the eating patterns of romantic partners. Several studies have identified the importance of environmental and social cues on consumer food consumption (Chernev and Gal 2010; McFerran et al. 2010; Wansink and Van Ittersum 2013; Wilcox et al. 2009), however, research is limited on how individuals are influenced by the food choices of their romantic partners. Here, we showed that food choice is not only driven by available environmental cues and associations that consumers hold toward food, but that relationship motives also play an important role in determining what consumers eat.

Implications for Policy and Well-Being

Our research also offers a variety of implications which could improve consumers' eating habits and overall well-being. For instance, when couples go out to eat, they should be aware of their underlying relationship motives. Females should realize that when they initially attempt to form a relationship with a romantic partner, their tendency will be to match the eating style of their male partners. Either choosing a partner who eats healthy or consciously overriding underlying motives by eating healthy as an appearance-enhancing technique should aid females in maintaining a healthy diet. Interestingly, a non-conformist strategy is preferred by some men when initially forming relationships (Hornsey et al. 2015). Therefore, females could not only maintain a healthy diet by avoiding influence from unhealthy eating partners, but could also potentially increase their partner's interest in a relationship by not matching the eating habits of their male counterparts. Conversely, for females with a relationship maintenance motive, the focus should now be entirely on eating healthy. Since a male with a maintenance motive is likely 
to defer to the choices of their female partners, encouraging women to make healthy food decisions for the couple could be a powerful way for women to feel like they are helping both themselves and their partners make positive food choices.

Males, on the other hand, should be cognizant of their maintenance behaviors. Males who are committed to a female partner become more influenced by partner's behavior and thus are more likely to be influenced by a female's eating patterns. If the female eats unhealthy, the male is in a difficult situation. Their underlying tendency is to defer to their partner, and thus, they are compelled to conform. However, males must override this powerful underlying motive by downplaying or disregarding these natural tendencies to delicately assert their independence in food choice. Thus, a nutrition intervention for males should focus on encouraging independence and healthy food choice during relationship maintenance. Next, we discuss the limitations of our findings and provide areas for future research.

\section{Limitations and Future Research}

While our research provides insights on how relationship motives impact food choice, some limitations should be noted. First, although our findings highlighted the impact of relationship formation and maintenance motives, a third motive may also be shared by individuals in relationships. Parenting motives relate to both a male and female's degree of commitment and drive to raising shared offspring (Kenrick et al. 2010). Because shared offspring can also contribute to group decision making and that more fundamental evolutionary needs related to safety and health are activated when caring for children (Griskevicius and Kenrick 2013), studying parenting motives was beyond the scope of our focus on how romantic 
partners influence each other. Previous research has identified that parenting styles impact the healthiness of children's food consumption (Bassett, Chapman, and Beagan 2008; Kremers et al. 2003). Additional research could examine relationship satisfaction between spouses when parenting motives are active and how this satisfaction influences food choices for the family unit. We examined how individuals may be influenced by the food choices of their romantic partners. However, food choice is only one area where couples make joint decisions during relationship formation and maintenance. Future research should examine whether our observed effects extend to other domains. For example, couples may make joint financial decisions (e.g., whether to buy or rent a home, how to invest savings) during relationship maintenance. How romantic partners may influence each other outside of food choice is less clear, as prior research suggests that couples may use various influence strategies to impact their partner (Kim and Lee 1996; Park 1982) or trust their partner's expertise (Simpson et al. 2012) to facilitate joint decision making. Examining joint decision making strategies within the context of romantic relationships remains a fruitful area for additional exploration.

In a similar vein, it is also important to consider whether our observed shift in relational influence occurs in other domains as well. Future research should test whether this shift in relational influence is specific to food, general to joint decision making, or impacted by the nature of the decision. Given that men often desire harmony in joint decision making with their spouses (Buss and Shackelford 1997; de Miguel and Buss 2011; Kardum et al. 2006), relational influence may shift towards women in any domain where men's involvement is relatively limited (thus preserving relationship harmony). Conversely, in decisions where involvement is increased, men may be more willing to assert themselves and potentially engage in conflict with their partners. However, additional research is needed to better understand when women possess 
relational influence over men during relationship maintenance and what factors impact this effect.

Future research could also examine the role of licensing relative to our findings. For females in relationship formation, indulging based on her partner's unhealthy choices could imply a licensing effect. However, evidence of relational influence was found across both healthy and unhealthy dining partners. Additionally, it does not explain our results in regards to men and relationship maintenance. Prior research has identified that men generally have a reduced interest in healthy eating and nutrition when in a committed relationship (Newcombe et al. 2012; Wardle et al. 2004). Thus, a partner's healthy eating choices are likely to impact them positively, whereas a partner's unhealthy choices would not affect their natural tendencies.

Across our four studies, we limited tests of our conceptual model to male-female couples. However, we expect members of same-sex and polyamorous relationships to also influence each other's food decisions. Research should examine each individual's role(s) within these relationships to better understand when food choices will be impacted. Furthermore, individuals may also identify as transsexual or gender-fluid. Future research could examine the food choices of these individuals during transitional periods to gain important insights on how others may influence their decision making.

Our primary outcome for food choice was the healthiness or unhealthiness of one's food selections. While this outcome has important ties to individual health and well-being, there are several other important food outcomes that could be examined. Research should also consider whether variety preferences in food choice are also impacted by various relationship motives. For example, Ariely and Levav (2000) examine how group settings influence choice variety in food and drink consumption. Future research could extend those findings by specifically 
examining romantic relationships and how relationship motives either promote or inhibit trial of new foods and variety-seeking behaviors in the food domain.

An additional limitation of our work was that we only examined food decisions at a single point in time. Given that approximately half of a couple's meals are shared (Sobal and Nelson 2003), it is important to consider how a couple's food choices evolve over the course of a relationship and how eating habits change over time. By identifying when couples are likely to shift toward unhealthy eating habits, this could assist nutritionists and policy makers in the development of interventions designed to help couples eat healthier.

In conclusion, the current research demonstrates that a powerful source of influence in food choice decisions comes from one's romantic partner. Based on differences in perceptions of relational influence, women (men) were more likely to be impacted by their partner's food choices during relationship formation (maintenance). Future research should continue to examine the ways in which romantic partners influence each other's decision making. 


\section{DATA COLLECTION INFORMATION}

The third author collected data for study 1 from a national restaurant chain with several locations in the Miami, Florida, area in spring 2016. The first author collected data for study 2 through the marketing department subject pool at the University of Central Florida in February 2017. The first and second authors collected data for study 3 through Amazon Mechanical Turk in January and February 2017. The first and second authors collected data for study 4 through Amazon Mechanical Turk in March 2017. These data were analyzed jointly by all three authors. 


\section{Appendix}

Study 1 Moderation Analysis (PROCESS Model 1)

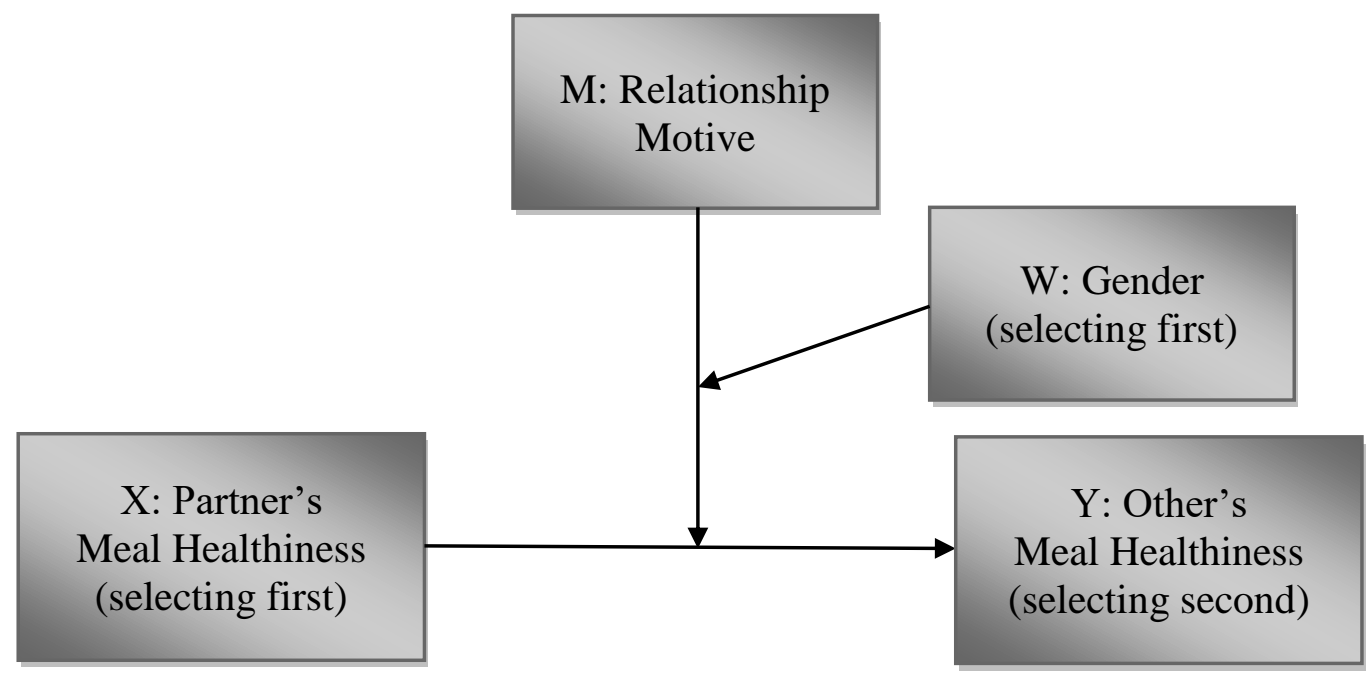

$\underline{\text { Study } 2 \text { Relationship Scenarios }}$

Relationship Formation (males)

Imagine you are at a party and you are single. At the party, you are meeting several highly attractive and friendly women. One of the women initiates a conversation with you and you both enjoy each other's company. She begins to flirt with you and you are truly enjoying getting to know her. As the party ends, the woman walks you home and gives you a passionate kiss. You look forward to the next time you will see her.

\section{Relationship Formation (females)}

Imagine you are at a party and you are single. At the party, you are meeting several highly attractive and friendly men. One of the men initiates a conversation with you and you both enjoy each other's company. He begins to flirt with you and you are truly enjoying getting to know him. As the party ends, the man walks you home and gives you a passionate kiss. You look forward to the next time you will see him.

\section{Relationship Maintenance (males)}

Imagine you are at a party with your girlfriend. Your girlfriend is being highly attentive and affectionate towards you. During the party, it feels as if you are the only two people in the room. You talk, laugh, and enjoy the evening together. You feel that spending time together helps reinforce your commitment to each other. As the evening goes on, you decide to go home. While heading home, you think about how wonderful it feels to be in a relationship with her. 
Relationship Maintenance (females)

Imagine you are at a party with your boyfriend. Your boyfriend is being highly attentive and affectionate towards you. During the party, it feels as if you are the only two people in the room. You talk, laugh, and enjoy the evening together. You feel that spending time together helps reinforce your commitment to each other. As the evening goes on, you decide to go home. While heading home, you think about how wonderful it feels to be in a relationship with him.

\section{Study 3 Relationship Scenarios}

Relationship Formation (boss)

Imagine you just started a new job and you are at a company party. At the party, it is the first time you are interacting with your new boss. Your boss initiates a conversation with you and you begin getting to know each other. You talk and laugh as you learn about each other's interests and hobbies. As the party ends, you decide to go home. You look forward to starting your new job and your relationship with your new boss.

Relationship Maintenance (boss)

Imagine you are at a company party with your boss. You have known your boss for a long time, and they are being very friendly and conversational with you at the party. During the party, you reminisce about your work relationship and your boss seems to be having a good time. You talk, laugh, and enjoy hanging out outside of the workplace. During the evening, you learn new things about each other and build a closer relationship. As the evening goes on, you decide to go home. While heading home, you feel this time together will help grow your relationship.

$\underline{\text { Study } 4 \text { - Perceptions of Relational Influence }}$ (All items measured on 7-point bipolar scales with endpoints in parentheses. Lower scores represent men possessing greater relational influence, while higher scores represent women possessing greater relational influence)

1. Who is more likely to persuade their partner when making food choices? (men are more likely to persuade women-women are more likely to persuade men)

2. Who is more likely to make decisions in the food domain? (men are more likely to make decisions-women are more likely to make decisions)

3 . Who tends to rely more on their partner when making food choice decisions? (women rely more on men-men rely more on women)

4. Prior to making food choice decisions, who is more likely to consult with their partner? (women are more likely to consult with men-men are more likely to consult with women) 5 . Who is more likely to take cues from their partner about what to eat? (women are more likely to take cues from men-men are more likely to take cues from women) 
Study 4 Mediation Analysis (PROCESS Model 15)

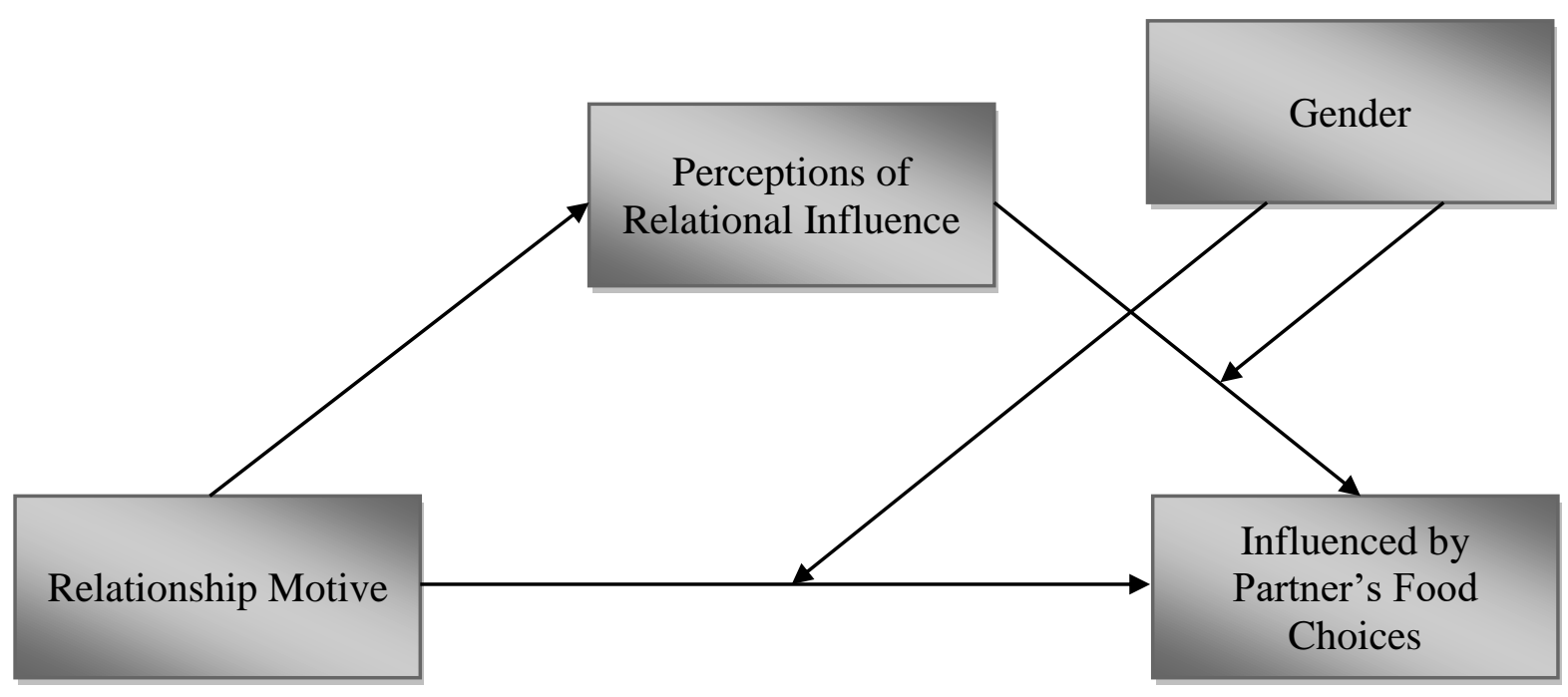


Relationship Slides (Study 4)

\section{Relationship Formation}

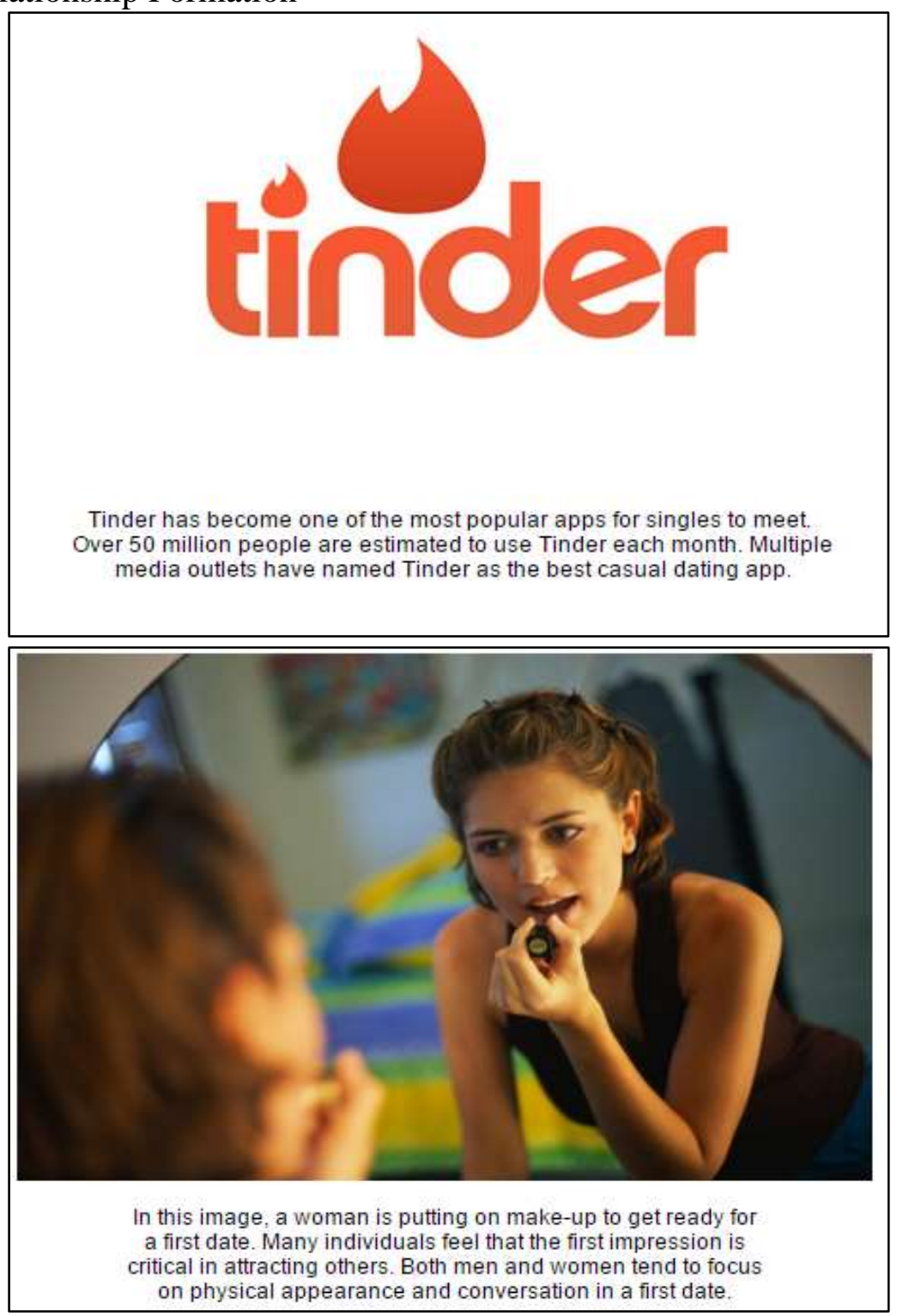

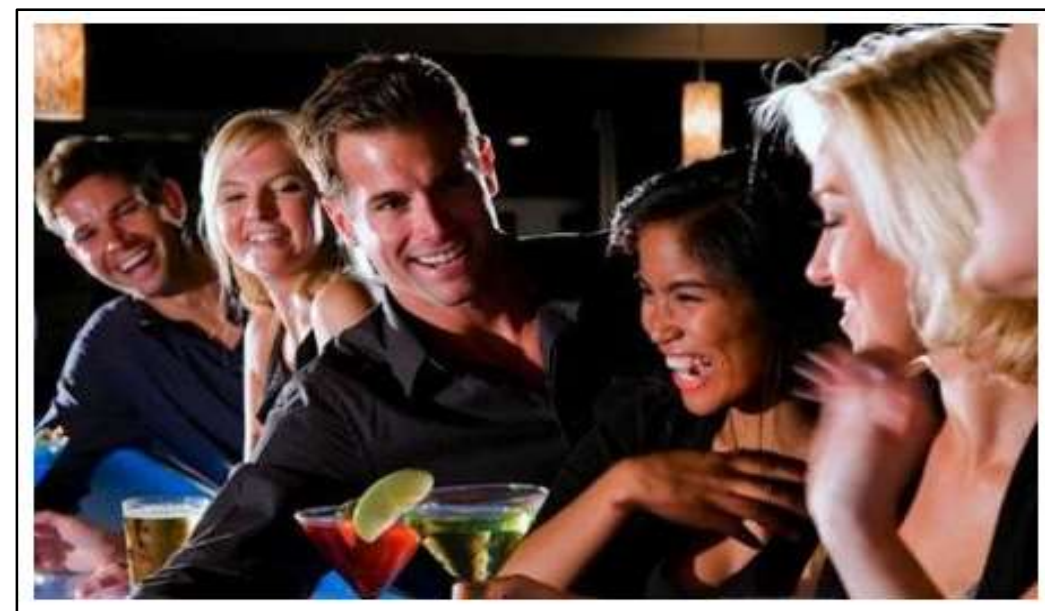

Perhaps the most popular location for singles to meet is at bars. The combination of friends, alcohol, and a social atmosphere often facilitates attraction and conversation among strangers.

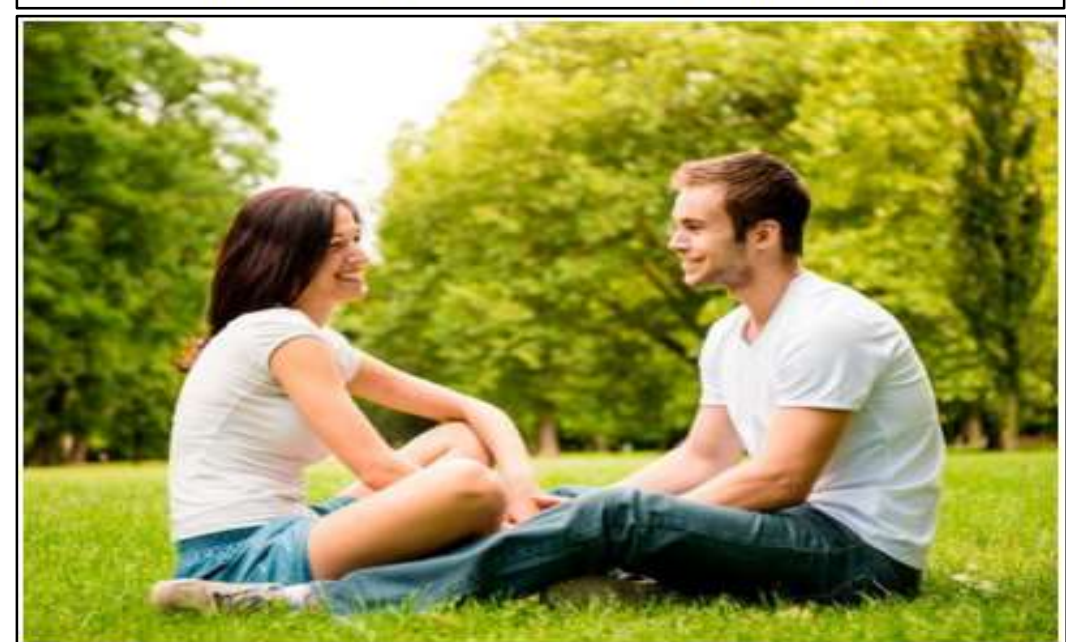

Many individuals prefer to go to a park on their first date. The combination of a public place with the peace and quiet to get to know someone is appealing to both males and females. 


\section{Relationship Maintenance}

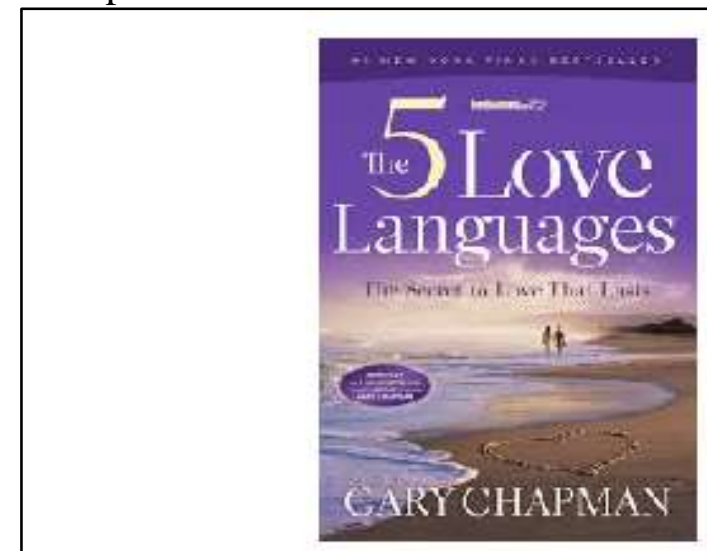

When couples enter a relationship, they often consider books like The 5 Love Languages. The book helps people understand the loving behaviors that their new relationship partner will value most and those behaviors that will make a partner feel the most loved.

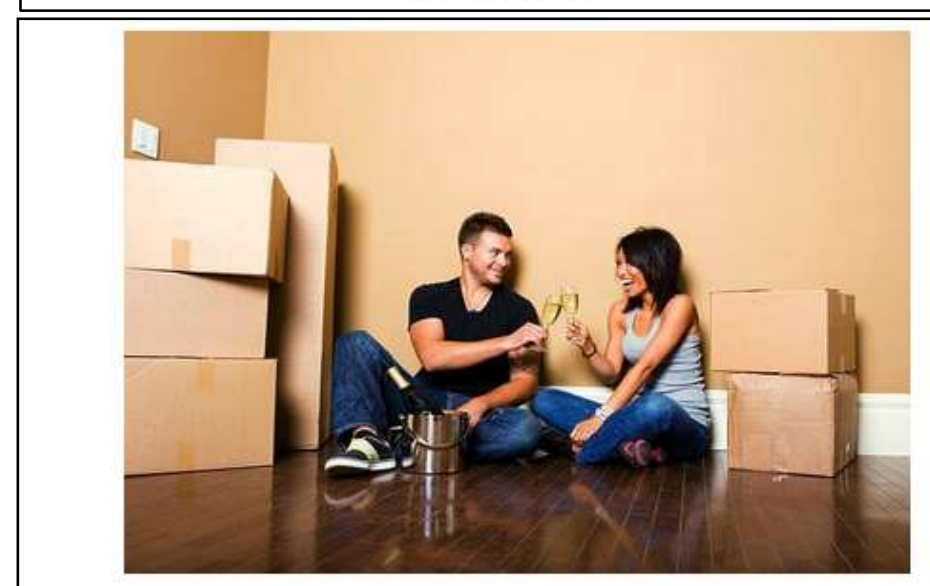

For individuals in relationships, commitment to each other often increases over time. Deciding to live together is a common choice for couples in a serious relationship. By age 30,3 in 4 people wil

live with, or have previously lived with, a significant other.

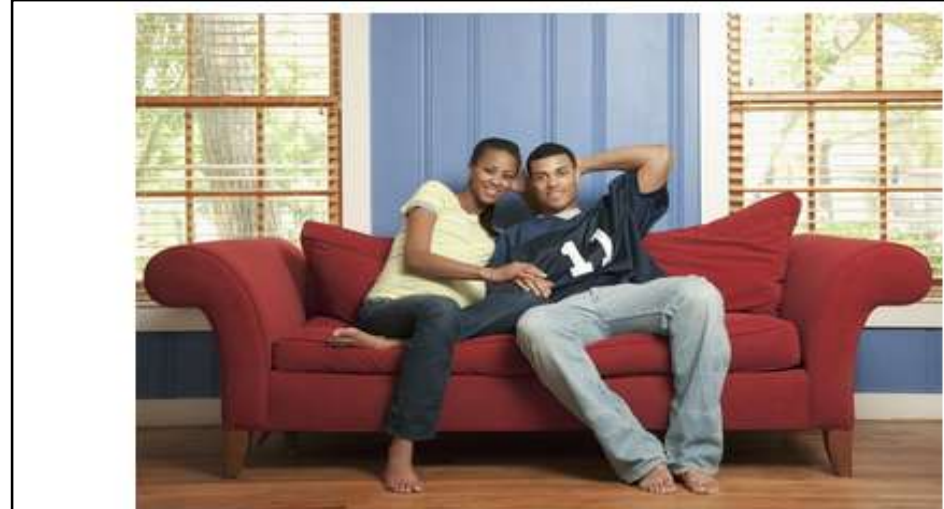

Recent research has identified that couples in committed relationships often engage in joint activities. For example, couples may talk about their day, watch TV shows together, or develop shared interests to reinforce and maintain their relationship.

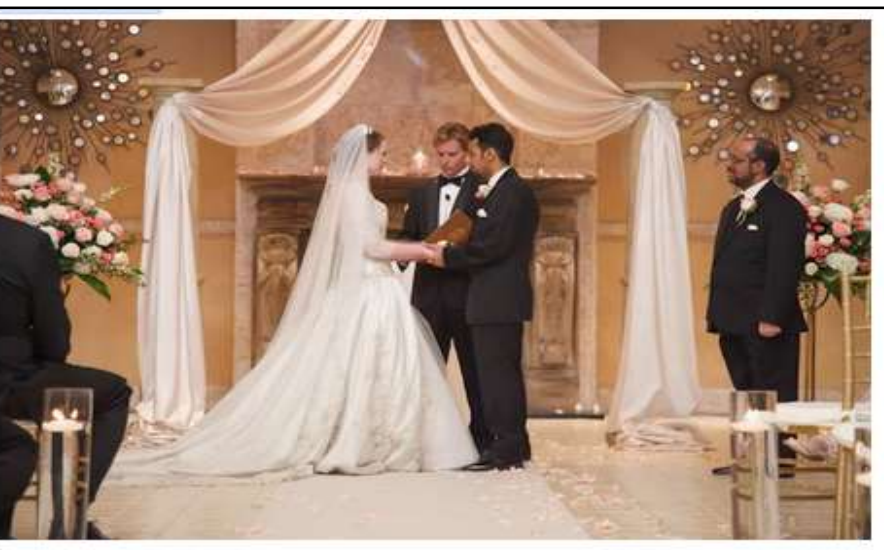

As a relationship matures, individuals must determine whether their partner is the right person for a long-term commitment. Marriage remains the most popular display of commitment for couples all over the world. Over 2 million couples per year are married in the United States alone. 


\section{REFERENCES}

Allen, Julie Ober, Derek M. Griffith, and Henry C. Gaines (2013), “'She Looks Out for the Meals, Period': African American Men's Perceptions of How their Wives Influence Their Eating Behavior and Dietary Health," Health Psychology, 32 (4), 447-55.

Amiraian, Dana E. and Jeffery Sobal (2009), "Dating and Eating. Beliefs about Dating Foods among University Students," Appetite, 53 (2), 226-32.

Ariely, Dan and Jonathan Levav (2000), "Sequential Choice in Group Settings: Taking the Road Less Traveled and Less Enjoyed," Journal of Consumer Research, 27 (3), 279-90.

Ashton-James, Claire, Rick B. Van Baaren, Tanya L. Chartrand, Jean Decety, and Johan Karremans (2007), "Mimicry and Me: The Impact of Mimicry on Self-Construal," Social Cognition, 25 (4), 518-35.

Bassett, Raewyn, Gwen E. Chapman, and Brenda L. Beagan (2008), “Autonomy and Control: The Co-Construction of Adolescent Food Choice," Appetite, 50 (2), 325-32.

Bearden, William O. and Randall L. Rose (1990), "Attention to Social Comparison Information: An Individual Difference Factor Affecting Consumer Conformity," Journal of Consumer Research, 16 (4), 461-71.

Bolino, Mark C. and William H. Turnley (1999), "Measuring Impression Management in Organizations: A Scale Development Based on the Jones and Pittman Taxonomy," Organizational Research Methods, 2 (2), 187-206.

Botwin, Michael D., David M. Buss, and Todd K. Shackelford (1997), "Personality and Mate Preferences: Five Factors in Mate Selection and Marital Satisfaction," Journal of Personality, 65 (1), 107-36.

Bove, Caron F., Jeffery Sobal, and Barbara S. Rauschenbach (2003), "Food Choices Among Newly Married Couples: Convergence, Conflict, Individualism, and Projects," Appetite, 40 (1), 25-41.

Bowlby, John (1969), Attachment and Loss: Attachment. New York: Basic Books.

Buss, David M. (1988), "The Evolution of Human Intrasexual Competition: Tactics of Mate Attraction," Journal of Personality and Social Psychology, 54 (4), 616-28.

Buss, David M. and Todd K. Shackelford (1997), "From Vigilance to Violence: Mate Retention Tactics in Married Couples," Journal of Personality \& Social Psychology, 72 (2), 346-61.

Campbell, Anne (2002), A Mind of Her Own: The Evolutionary Psychology of Women. Oxford, England: Oxford University Press. 
Campbell, Lorne, Jeffry A. Simpson, Deborah A. Kashy, and W. Steven Rholes (2001), "Attachment Orientations, Dependence, and Behavior in a Stressful Situation: An Application of the Actor-Partner Interdependence Model," Journal of Social and Personal Relationships, 18 (6), 821-43.

Carli, Linda L. (2001), “Gender and Social Influence,” Journal of Social Issues, 57 (4), 725-41.

Cavanaugh, Lisa A. (2016), "Consumer Behavior in Close Relationships," Current Opinion in Psychology, 10 (1), 101-6.

Chernev, Alexander and David Gal (2010), "Categorization Effects in Value Judgments: Averaging Bias in Evaluating Combinations of Vices and Virtues," Journal of Marketing Research, 47 (4), 738-47.

Christensen, Andrew (1987), "Detection of Conflict Patterns in Couples," In Understanding Major Mental Disorder: The Contribution of Family Interaction Research, Ed. K. Hahlweg and M. J. Goldstein, New York: Family Process Press, 250-65.

Cialdini, Robert B. and Melanie R. Trost (1998), "Social Influence: Social Norms, Conformity, and Compliance," in The Handbook of Social Psyhology, Vol. 2, $4^{\text {th }}$ ed., Ed. Daniel T. Gilbert and Susan T. Fiske, New York: McGraw-Hill, 151-92.

Cross, Susan E. and Laura Madson (1997), "Models of the Self: Self-Construals and Gender," Psychological Bulletin, 122 (1), 5-37.

Dahl, Darren (2013), "Social Influence and Consumer Behavior," Journal of Consumer Research, 40 (2), iii-v.

de Miguel, Adelia and David M. Buss (2011), "Mate Retention Tactics in Spain: Personality, Sex Differences, and Relationship Status," Journal of Personality, 79 (3), 563-86.

DeVault, Marjorie L. (1994), Feeding the Family: The Social Organization of Caring as Gendered Work. University of Chicago Press.

Diekman, Amanda B., Wind Goodfriend, and Stephanie Goodwin (2004), "Dynamic Stereotypes of Power: Perceived Change and Stability in Gender Hierarchies," Sex Roles, 50 (3), 20115.

Donnellan, M. Brent, Rand D. Conger, and Chalandra M. Bryant (2004), "The Big Five and Enduring Marriages," Journal of Research in Personality, 38 (5), 481-504.

Durante, Kristina M. and Ashley Rae Arsena (2015), "Playing the Field: The Effect of Fertility on Women's Desire for Variety," Journal of Consumer Research, 41 (6), 1372-91.

Durante, Kristina M., Paul W. Eastwick, Eli J. Finkel, Steven W. Gangestad, and Jeffry A. Simpson (2016), "Pair-Bonded Relationships and Romantic Alternatives: Toward an 
Integration of Evolutionary and Relationship Science Perspectives," Advances in Experimental Social Psychology, 53 (1), 1-74.

Durante, Kristina M., Vladas Griskevicius, Joseph P. Redden, and Andrew Edward White (2015), "Spending on Daughters versus Sons in Economic Recessions," Journal of Consumer Research, 42 (3), 435-57.

Eastwick, Paul W. and Eli J. Finkel (2008), "Sex Differences in Mate Preferences Revisited: Do People Know What They Initially Desire in a Romantic Partner?" Journal of Personality and Social Psychology, 94 (2), 245-64.

Greenlees, Ian A. and William C. McGrew (1994), "Sex and Age Differences in Preferences and Tactics of Mate Attraction: Analysis of Published Advertisements," Ethology and Sociobiology, 15 (2), 59-72.

Griskevicius, Vladas, and Douglas T. Kenrick (2013), "Fundamental Motives: How Evolutionary Needs Influence Consumer Behavior," Journal of Consumer Psychology, 23 (3), 372-86.

Hayes, Andrew F. (2013), Introduction to Mediation, Moderation, and Conditional Process Analysis: A Regression-Based Approach. New York: Guilford Press.

Hornsey, Matthew J., Richard Wellauer, Jason C. McIntyre, and Fiona K. Barlow (2015), “A Critical Test of the Assumption That Men Prefer Conformist Women and Women Prefer Nonconformist Men," Personality and Social Psychology Bulletin, 41 (6), 755-68.

Impett, Emily A., Amie M. Gordon, Aleksandr Kogan, Christopher Oveis, Shelly L. Gable, and Dacher Keltner (2010), "Moving toward More Perfect Unions: Daily and Long-Term Consequences of Approach and Avoidance Goals in Romantic Relationships," Journal of Personality and Social Psychology, 99 (6), 948-63.

Jackson, Ralph W., Stephen W. McDaniel, and C. P. Rao (1985), "Food Shopping and Preparation: Psychographic Differences of Working Wives and Housewives," Journal of Consumer Research, 12 (1), 110-13.

Kardum, Igor, Jasna Hudek-Knežević, and Asmir Gračanin (2006), "Sociosexuality and Mate Retention in Romantic Couples," Psihologijske Teme, 15 (2), 277-96.

Kelley, Harold H. and John W. Thibaut (1978), Interpersonal Relations: A Theory of Interdependence. New York: John Wiley and Sons, Inc.

Keltner, Dacher, Deborah H. Gruenfeld, and Cameron Anderson (2003), "Power, Approach, and Inhibition," Psychological Review, 110 (2), 265-84.

Kenrick, Douglas T., Vladas Griskevicius, Steven L. Neuberg, and Mark Schaller (2010), "Renovating the Pyramid of Needs," Perspectives on Psychological Science, 5 (3), 292314. 
Kim, Chankon and Hanjoon Lee (1996), "A Taxonomy of Couples based on Influence Strategies: The Case of Home Purchase," Journal of Business Research, 36 (2), 157-68.

Kirchler, Erich (2001), Conflict and Decision-Making in Close Relationships: Love, Money, and Daily Routines. United Kingdom: Psychology Press.

Kirkpatrick, Lee A. and Keith E. Davis (1994), "Attachment Style, Gender, and Relationship Stability: A Longitudinal Analysis," Journal of Personality and Social Psychology, 66 (3), 502-12.

Kremers, Stef P. J., Johannes Brug, Hein de Vries, and Rutger C. M. E. Engels (2003), "Parenting Style and Adolescent Fruit Consumption," Appetite, 41 (1), 43-50.

Lee, Christina K. C. and Sharon E. Beatty (2002), "Family Structure and Influence in Decision Making," Journal of Consumer Marketing, 19 (1), 21-41.

Lennox, Richard D. and Raymond N. Wolfe (1984), "Revision of the Self-Monitoring Scale," Journal of Personality and Social Psychology, 46 (6), 1349-64.

Luo, Shanhong and Guangjian Zhang (2009), "What Leads to Romantic Attraction: Similarity, Reciprocity, Security, or Beauty? Evidence from a Speed-Dating Study," Journal of Personality, 77 (4), 933-64.

Malouff, John M., Einar B. Thorsteinsson, Nicola S. Schutte, Navjot Bhullar, and Sally E. Rooke (2010), "The Five-Factor Model of Personality and Relationship Satisfaction of Intimate Partners: A Meta-Analysis," Journal of Research in Personality, 44 (1), 124-7.

McFerran, Brent, Darren W. Dahl, Gavan J. Fitzsimons, and Andrea C. Morales (2010), "I'll Have What She's Having: Effects of Social Influence and Body Type on the Food Choices of Others," Journal of Consumer Research, 36 (6), 915-29.

Newcombe, Mark A., Mary B. McCarthy, James M. Cronin, and Sinéad N. McCarthy (2012), “"Eat Like a Man". A Social Constructionist Analysis of the Role of Food in Men's Lives," Appetite, 59 (2), 391-8.

Nickols, Sharon Y. and Karen D. Fox (1983), "Buying Time and Saving Time: Strategies for Managing Household Production," Journal of Consumer Research, 10 (2), 197-208.

Overall, Nickola C., Garth J. O. Fletcher, Jeffry A. Simpson, and Chris G. Sibley (2009), "Regulating Partners in Intimate Relationships: The Costs and Benefits of Different Communication Strategies," Journal of Personality and Social Psychology, 96 (3), 62039.

Park, C. Whan (1982), "Joint Decisions in Home Purchasing: A Muddling-Through Process," Journal of Consumer Research, 9 (2), 151-62. 
Roberts, Mary Lou and Lawrence H. Wortzel (1979), "New Life-Style Determinants of Women's Food Shopping Behavior,” The Journal of Marketing, 43 (3), 28-39.

Rose, Suzanna and Irene Hanson Frieze (1993), "Young Singles' Contemporary Dating Scripts," Sex Roles, 28 (9-10), 499-509.

Simpson, Jeffry A., Vladas Griskevicius, and Alexander J. Rothman (2012), "Consumer Decisions in Relationships," Journal of Consumer Psychology, 22 (3), 304-314.

Sobal, Jeffery and Mary K. Nelson (2003), "Commensal Eating Patterns: A Community Study," Appetite, 41 (2), 181-90.

Stets, Jan E. and Stacy A. Hammons (2002), "Gender, Control, and Marital Commitment," Journal of Family Issues, 23 (1), 3-25.

Su, Chenting, Kevin Zheng Zhou, Nan Zhou, and Julie Juan Li (2008), "Harmonizing Conflict in Husband-Wife Purchase Decision Making: Perceived Fairness and Spousal Influence Dynamics," Journal of the Academy of Marketing Science, 36 (3), 378-94.

Sundie, Jill M., Douglas T. Kenrick, Vladas Griskevicius, Joshua M. Tybur, Kathleen D. Vohs, and Daniel J. Beal (2011), "Peacocks, Porsches, and Thorstein Veblen: Conspicuous Consumption as a Sexual Signaling System," Journal of Personality \& Social Psychology, 100 (4), 664-80.

Tran, SiSi and Jeffry A. Simpson (2009), "Prorelationship Maintenance Behaviors: The Joint Roles of Attachment and Commitment," Journal of Personality and Social Psychology, 97 (4), 685-98.

Van Lange, Paul A. M., Caryl E. Rusbult, Stephen M. Drigotas, Ximena B. Arriaga, Betty S. Witcher, and Chante L. Cox (1997), "Willingness to Sacrifice in Close Relationships,” Journal of Personality and Social Psychology, 72 (6), 1373-95.

Vartanian, Lenny R., C. Peter Herman, and Janet Polivy (2007), "Consumption Stereotypes and Impression Management: How You Are What You Eat,” Appetite, 48 (3), 265-77.

Wang, Yajin and Vladas Griskevicius (2014), "Conspicuous Consumption, Relationships, and Rivals: Women's Luxury Products as Signals to Other Women,” Journal of Consumer Research, 40 (5), 834-54.

Wansink, Brian and Koert van Ittersum (2013), "Portion Size Me: Plate-Size Induced Consumption Norms and Win-Win Solutions for Reducing Food Intake and Waste," Journal of Experimental Psychology: Applied, 19 (4), 320-32. 
Wardle, Jane, Anne M. Haase, Andrew Steptoe, Maream Nillapun, Kiriboon Jonwutiwes, and France Bellisie (2004), "Gender Differences in Food Choice: The Contribution of Health Beliefs and Dieting," Annals of Behavioral Medicine, 27 (2), 107-16.

Wilcox, Keith, Beth Vallen, Lauren Block, and Gavan J. Fitzsimons (2009) "Vicarious Goal Fulfillment: When the Mere Presence of a Healthy Option Leads to an Ironically Indulgent Decision," Journal of Consumer Research, 36 (3), 380-93.

Wood, Wendy (2000), “Attitude Change: Persuasion and Social Influence," Annual Review of Psychology, 51 (1), 539-70.

Zaichkowsky, Judith Lynne (1985), "Measuring the Involvement Construct," Journal of Consumer Research, 12 (3), 341-52. 


\section{Table 1}

Means of Perceptions of Relational Influence by Condition

\begin{tabular}{cccc}
\hline & Total & Males & Females \\
\hline Relationship & 3.84 & 4.06 & 3.68 \\
Formation & $(.88)$ & $(.92)$ & $(.80)$ \\
Relationship & 4.18 & 4.31 & 4.05 \\
Maintenance & $(.83)$ & $(.93)$ & $(.69)$ \\
\hline
\end{tabular}




\section{Figure 1}

Study 1 Results
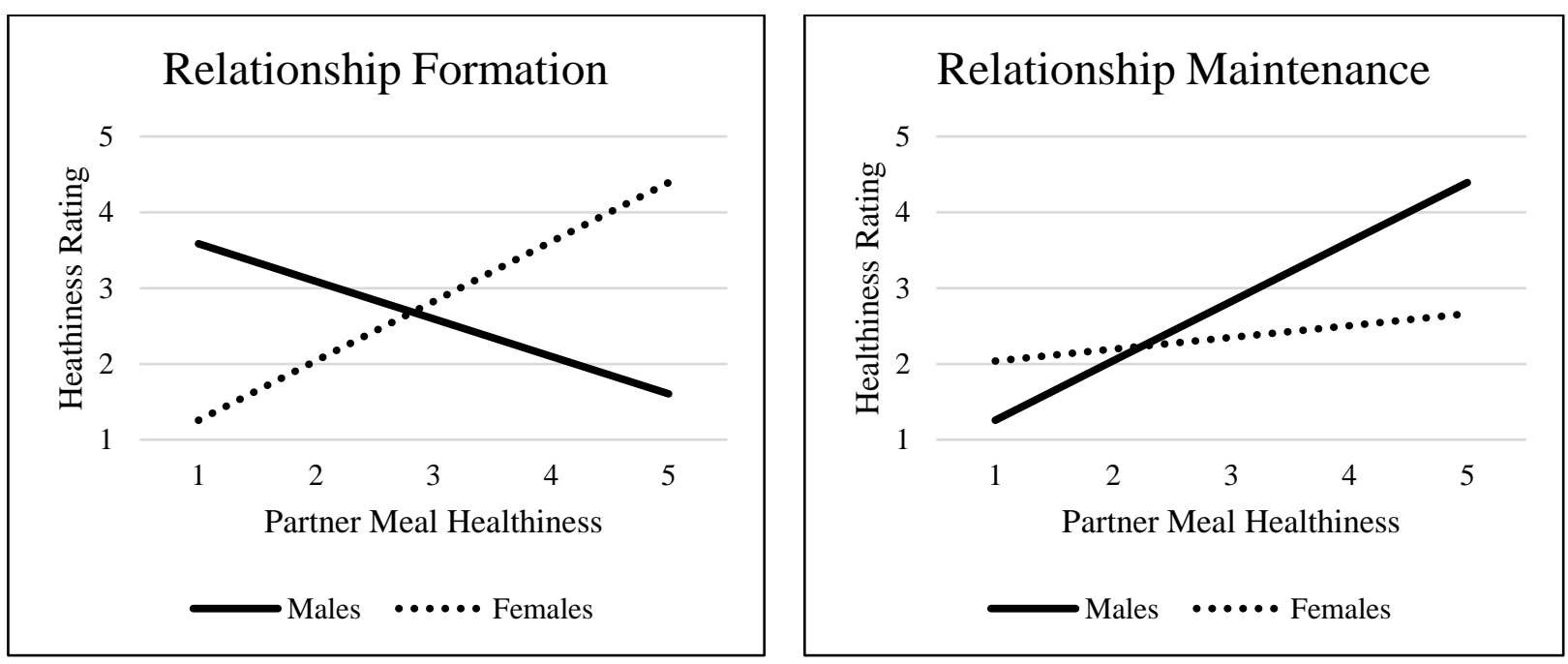


\section{Figure 2}

Study 2 Results

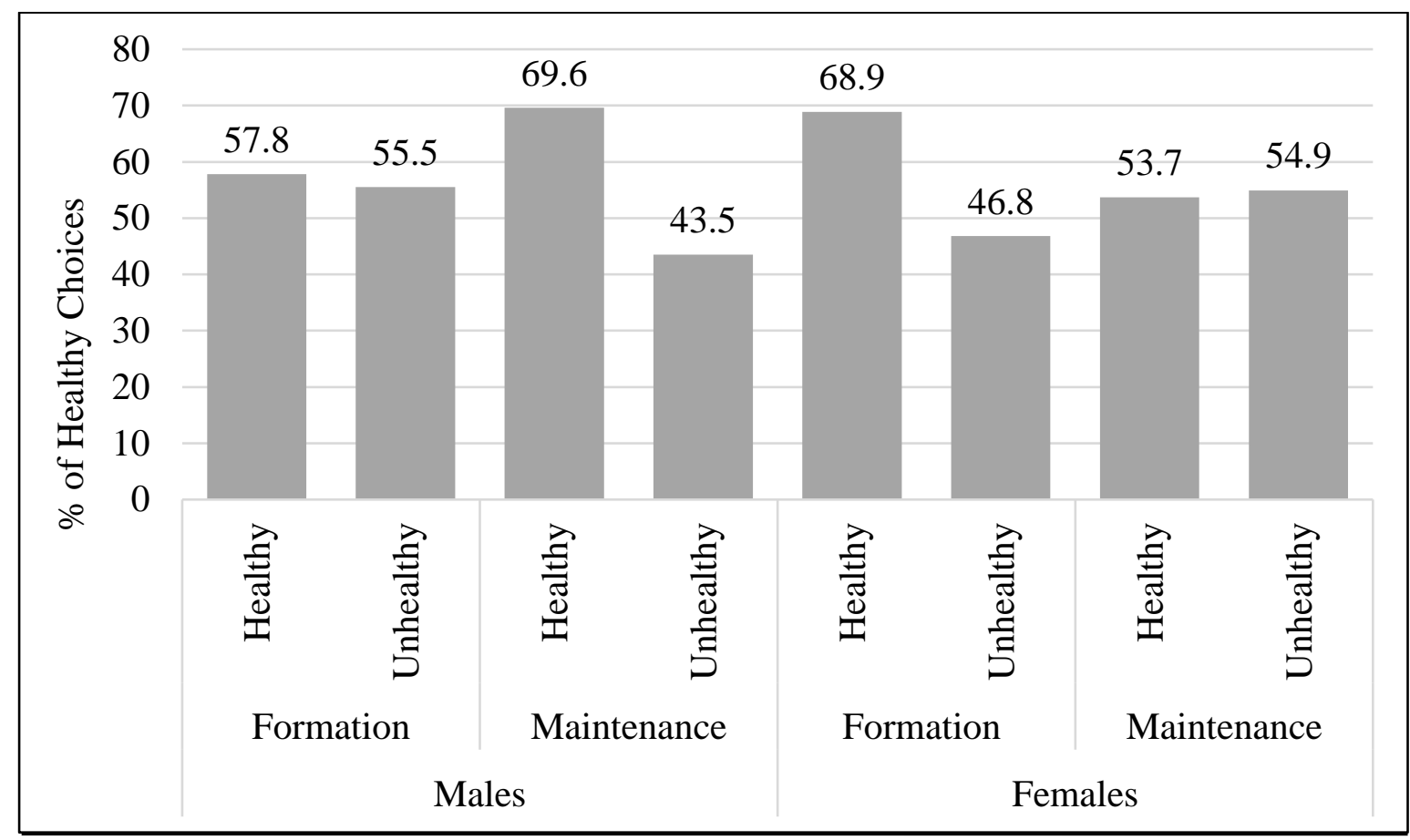




\section{Figure 3}

\section{Study 3 Results}

Panel A: Dining with Romantic Partner

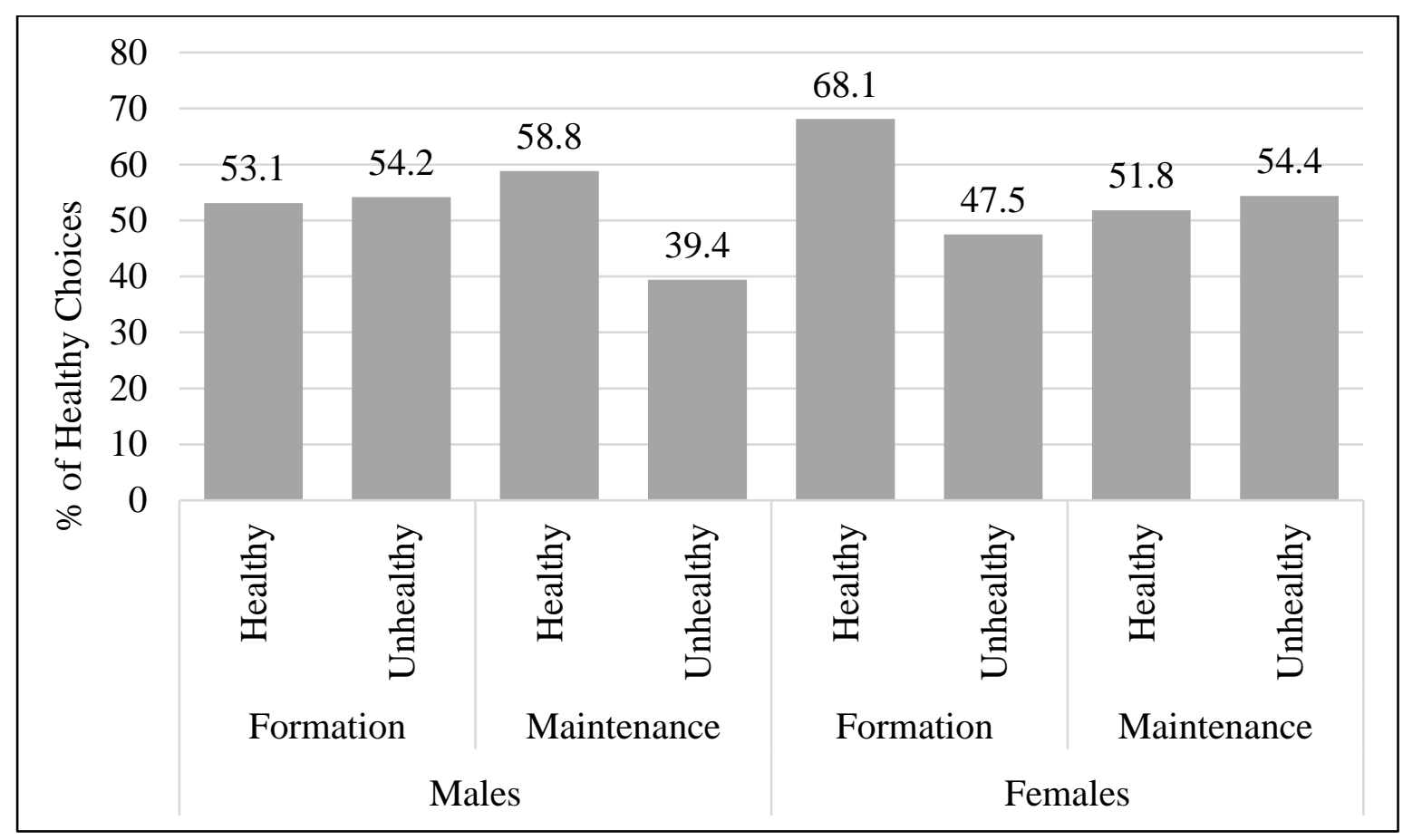

Panel B: Dining with Boss

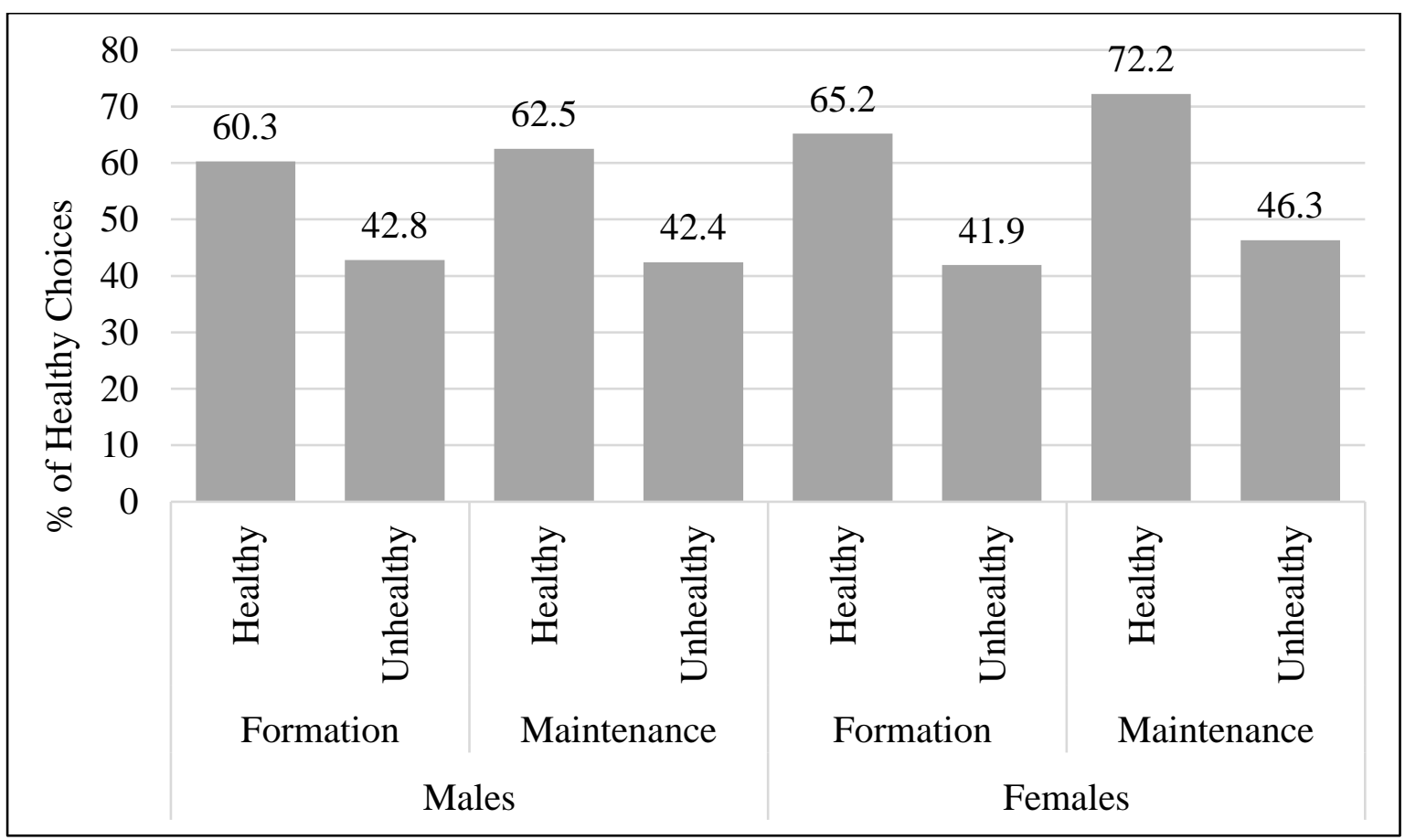




\section{Figure 4}

\section{Study 4 Results}

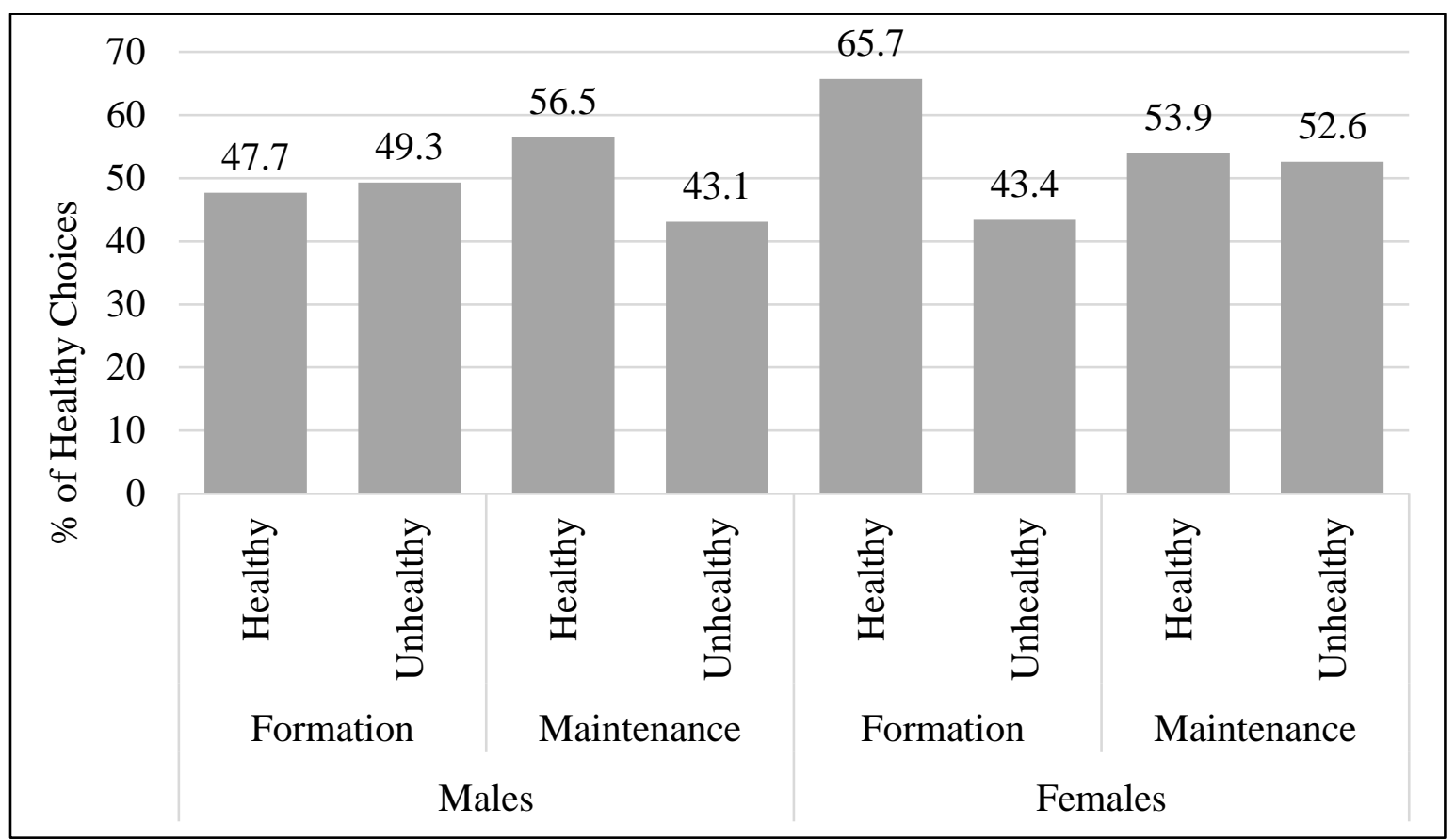




\section{Headings List}

1) Conceptual Background

2) Relationship Formation

2) Relationship Maintenance

2) Plan of Studies

1) Study 1: Field Study of Relationships and Influence in Food Choice

2) Method

2) Results

2) Discussion

1) Study 2: Manipulating Relationship Motives

2) Method

2) Results

3) Manipulation Checks

3) Relationship Motives and Food Choice

2) Discussion

1) Study 3: Examining Differences in Relational Influence

2) Method

2) Results

3) Manipulation Checks

3) Relationship Motives and Food Choice

3) Dining with Romantic Partner

3) Dining with Boss

2) Discussion

1) Study 4: Test of Conceptual Model

2) Method

2) Results

3) Manipulation Checks

3) Relationship Motives and Food Choice

3) Perceptions of Relational Influence

3) Mediation Analysis

2) Discussion

1) General Discussion

2) Theoretical Contributions

2) Implications for Policy and Well-Being

2) Limitations and Future Research

1) Data Collection Information

1) References 